\title{
Climate change in the northeastern US: regional climate model validation and climate change projections
}

\author{
Fangxing Fan • Raymond S. Bradley • \\ Michael A. Rawlins
}

Received: 22 February 2013/Accepted: 21 May 2014/Published online: 1 June 2014

(C) The Author(s) 2014. This article is published with open access at Springerlink.com

\begin{abstract}
A high resolution regional climate model (RCM) is used to simulate climate of the recent past and to project future climate change across the northeastern US. Different types of uncertainties in climate simulations are examined by driving the RCM with different boundary data, applying different emissions scenarios, and running an ensemble of simulations with different initial conditions. Empirical orthogonal functions analysis and K-means clustering analysis are applied to divide the northeastern US region into four climatologically different zones based on the surface air temperature (SAT) and precipitation variability. The RCM simulations tend to overestimate SAT, especially over the northern part of the domain in winter and over the western part in summer. Statistically significant increases in seasonal SAT under both higher and lower emissions scenarios over the whole RCM domain suggest the robustness of future warming. Most parts of the northeastern US region will experience increasing winter precipitation and decreasing summer precipitation, though the changes are not statistically significant. The greater magnitude of the projected temperature increase by the end of the twenty-first century under the higher emissions scenario emphasizes the essential role of emissions choices in determining the potential future climate change.
\end{abstract}

Keywords Regional climate change - Regional climate model simulation $\cdot$ Northeastern US

Electronic supplementary material The online version of this article (doi:10.1007/s00382-014-2198-1) contains supplementary material, which is available to authorized users.

F. Fan $(\bowtie) \cdot$ R. S. Bradley $\cdot$ M. A. Rawlins

Department of Geosciences, University of Massachusetts,

611 North Pleasant Street, Amherst, MA 01003, USA

e-mail: fangxing@geo.umass.edu

\section{Introduction}

Global and regional climates are changing with the accelerating consumption of fossil fuel, and the profound impacts of climate change on humans and the natural environment have already been experienced across the northeastern US. The potential future impacts for climatesensitive sectors, including coastal regions, marine fisheries, forests, agriculture, winter recreation, and human health, have been addressed by a set of previous studies (Frumhoff et al. 2008; Kirshen et al. 2008; Fogarty et al. 2008; Iverson et al. 2008). Given the distinctive regional impacts and responses to climate change, it is of considerable importance to investigate possible future climate change at the regional scale. These future climate projections can provide underlying climate science information for impacts assessments and development of effective mitigation and adaptation strategies.

Based on outputs from nine coupled atmosphere-ocean general circulation models (AOGCMs), a hydrological model [i.e., the Variable Infiltration Capacity (VIC) model], and Spring Indices models (i.e., a suite of models that simulate the spring phenology of representative plants based on daily maximum and minimum temperature data; see Schwartz et al. 2006), Hayhoe et al. (2007) assessed future changes in climate, hydrological, and biological indicators across the northeastern US. It was found that these indicators are projected to change consistent with a warming climate, and the magnitude of their future trends are much larger under the higher emissions scenario than under the lower scenario. As climate simulations and projections by coarse resolution GCMs lack the regional details for impacts studies, different downscaling methods have been developed to derive finer resolution information from the GCM output. Statistical downscaling and regional 
climate modeling are two primary downscaling approaches. While statistical downscaling estimates the corresponding regional characteristics based on the established statistical relationships between the large-scale and local variables (Hewitson and Crane 2006; Ning et al. 2012), regional climate modeling applies sophisticated regional climate models (RCMs) consistent with their driving GCMs in the large-scale features to directly simulate the dynamics of the regional climate. The North American Regional Climate Change Assessment Program (NARCCAP) (Mearns et al. 2009, 2012) archived outputs from multiple RCM simulations driven by different GCMs to provide high resolution climate scenarios over North America. By analyzing climate projections from nine NARCCAP GCM-RCM pairs, Rawlins et al. (2012) found a significant increase in seasonal air temperature, a significant increase in winter precipitation, and a decrease in summer precipitation across the northeast US during the mid twenty-first century relative to the end of the twentieth century.

The uncertainties of the future climate projections exist due to the emissions scenario uncertainty, the uncertainty in the response of climate, and the natural variability uncertainty. The emissions scenario uncertainty and the natural variability uncertainty can be addressed by making climate projections under a range of emissions scenarios and using an ensemble of projections with different initial conditions. The uncertainty in the climate response, which arises from our imperfect understanding of key processes and feedbacks in the climate system, can be accounted for by applying a variety of climate models under the same emissions scenario.

In this study, we perform regional climate simulations over the northeastern sector of the United States and adjacent parts of southern Canada, applying a high resolution RCM developed by the UK Hadley Centre. The objectives are to evaluate the ability of this RCM to reproduce observed climate and to assess the future climate change over the northeastern US. To complement the results produced by previous studies (Hayhoe et al. 2007; Rawlins et al. 2012), this study focuses on a much larger domain than the traditionally defined northeastern US region, and provides finer-scale regional climate simulations with a horizontal resolution of $25 \mathrm{~km}$. A set of experiments was designed to estimate different types of uncertainties in the present-day simulations and future projections. The RCM simulations were driven by different boundary data to evaluate the uncertainty due to our imperfect understanding of the climate system ("science uncertainty"). We also quantified the "natural variability uncertainty" by running an ensemble of RCM simulations with different initial conditions. In addition, the "emissions scenario uncertainty" was examined by projecting future climate change under both higher and lower emissions scenarios. This RCM has already been applied in many previous studies to evaluate the sensitivity of simulations to domain size (Jones et al. 1995; Bhaskaran et al. 1996) and to project greenhouse gas induced climate change in various regions (Urrutia and Vuille 2009; Karmalkar et al. 2011; McCarthy et al. 2011).

\section{Models, experiments, and methodology}

\subsection{A regional modeling system: PRECIS}

Providing REgional Climates for Impacts Studies (PRECIS) is a regional modeling system developed at the UK Hadley Centre for the purpose of providing regional-scale high resolution climate projections for impact studies (Jones et al. 2004). It is composed of the latest version of the Hadley Centre RCM, a graphical user interface which makes the experimental setup easier, and a visualisation and data-processing package to display and process the RCM output. PRECIS is quite flexible for applications over any area of the globe and computationally inexpensive to meet the growing demand for regional climate projections and adaptation studies. More detailed information on different components of PRECIS can be found in the handbook (Jones et al. 2004) and the technical manual (Wilson et al. 2011).

The current version of the PRECIS RCM (HadRM3P) was developed from an improved version of the atmospheric component (HadAM3P) of the Hadley Centre coupled atmosphere-ocean general circulation model (HadCM3) (Gordon et al. 2000). It is a limited-area highresolution atmospheric and land surface model with horizontal resolutions of 50 and $25 \mathrm{~km}$. The atmospheric component is a hydrostatic primitive model with a regular latitude-longitude grid in the horizontal and a hybrid vertical coordinate system. There are 19 vertical levels in the atmosphere and four levels in the soil. The atmosphere extends from the lowest at $\sim 50 \mathrm{~m}$ to the highest at $0.5 \mathrm{hPa}$ with terrain-following $\sigma$-coordinates for the bottom four levels, purely pressure coordinates for the top three levels and a combination in between (Simmons and Burridge 1981). Boundary conditions, derived either from reanalysis data [e.g., ERA40 provided by the European Centre for Medium-Range Weather Forecasts (ECMWF)] or from global climate model (GCM) integrations (e.g., the Hadley Centre's global atmosphere-only model HadAM3P), are required to provide the meteorological forcing for the RCM. These boundary conditions comprise lateral boundary conditions of atmospheric pressure at the surface, horizontal wind components, temperature and humidity through the depth of the atmosphere, and the necessary 
chemical species when the sulphur cycle is being modeled, as well as surface boundary conditions of sea surface temperature (SST) and sea-ice extent and thickness. These lateral boundary conditions are provided at the latitudinal and longitudinal edges of the model domain and updated every $6 \mathrm{~h}$, whereas the surface boundary conditions are only required over ocean and inland water points and updated every day. A relaxation technique is applied to drive the RCM values towards values interpolated from the large-scale driving fields across a four-point lateral buffer zone.

In order to provide high resolution regional climate projections consistent with the large-scale circulation from the GCM and to achieve maximum compatibility, the PRECIS RCM and its driving GCM employ identical dynamical and physical formulations, apart from certain details (e.g., horizontal diffusion) which are dependent on resolution. Physical parameterizations of clouds, precipitation, radiative processes, boundary layer and the land surface are represented by their respective schemes and included as source and sink functions in the equations to modify the meteorological state variables. The radiation scheme, including the seasonal and diurnal cycles of incoming solar radiation, computes short wave and long wave fluxes which depend on atmospheric temperature and humidity, concentrations of radiatively active gases, clouds and sulphate aerosol concentrations. Both the direct effect (i.e., scattering and absorption of incoming solar radiation) and the first indirect effect [i.e., aerosols acting as cloud condensation nuclei $(\mathrm{CCN})]$ of sulphate aerosols are modeled. The land surface scheme employed is MOSES (Met Office Surface Exchange Scheme, Cox et al. 1999), and there is the option of using a more advanced scheme MOSES2.2 than the default MOSES1 in the latest version of the PRECIS RCM. Surface characteristics over land are prescribed based on a $1^{\circ} \times 1^{\circ}$ global dataset of vegetation and soil types of Wilson and Henderson-Sellers (1985). The surface hydrology scheme includes a vegetative canopy which intercepts some of the rainfall by both retaining water and evaporating it back to the atmosphere. The soil model uses a four-layer scheme to simulate soil hydrology and thermodynamics. The soil layer thicknesses, which are $0.1,0.25,0.65$ and $2.0 \mathrm{~m}$ from the top to the bottom, are chosen to resolve both the diurnal and seasonal cycles with minimal distortion.

\subsection{Experimental design}

The model domain selected for this study covers the eastern US, parts of Canada and the surrounding oceans (Fig. 1). The boundaries are placed over plains and oceans. The western boundary is away from the complex terrain in the western US to avoid the noise due to the mismatch

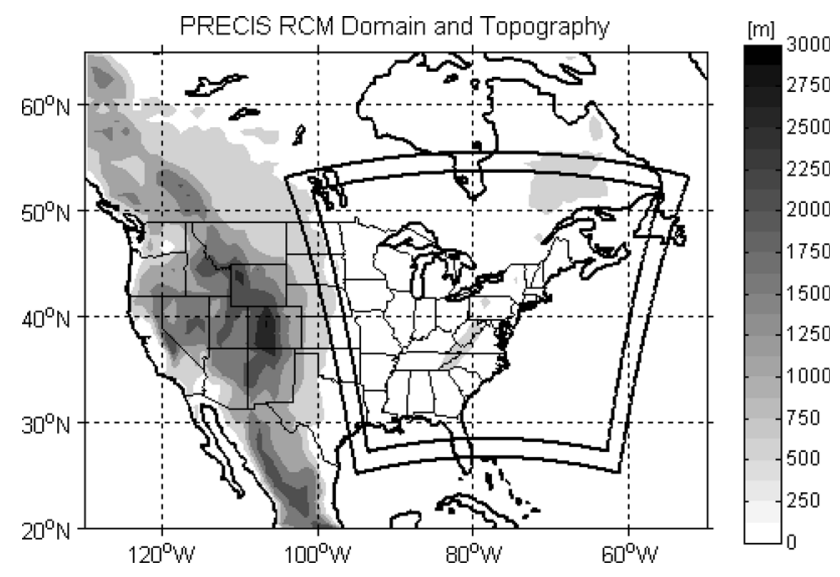

Fig. 1 PRECIS RCM domain and topography. The area between the outer and inner rectangles is the lateral buffer zone where the RCM values are relaxed towards the coarse resolution driving data. This rim of 8 grid points has been excluded from the analysis

between the coarse resolution driving data and the high resolution RCM topography in the interior adjacent to the buffer zone. Our region of interest, the northeastern US, is in the centre of the domain and well away from the lateral buffer zone.

We performed the following experiments at a horizontal resolution of $0.22^{\circ} \times 0.22^{\circ}$ latitude/longitude (a grid spacing of $25 \mathrm{~km}$ ) to simulate both climates of the recent past and future: (1) One RCM baseline simulation driven by a quasi-observed set of boundary data derived from ERA40 during the 1957-2002 interval [RCM (ERA40) BL], (2) three RCM baseline simulations driven by three 31-year integrations of HadAM3P during the 1960-1990 interval [RCM (HadAM3P) BL \#1-3], (3) three RCM simulations driven by HadAM3P during the 2070-2100 interval with the SRES A2 emissions scenario [RCM (HadAM3P) SRES A2 \#1-3], and (4) One single realization driven by HadAM3P during the 2070-2100 interval with the SRES B2 emissions scenario [RCM (HadAM3P) SRES B2]. The descriptions of these experiments in terms of the source of the boundary data and the relevant emissions scenarios are listed in Table 1 . The three ensemble members of the driving HadAM3P, using the same evolution of atmospheric composition, are initialized with different atmospheric and land surface states. Accordingly, the three RCM ensemble members for both current ["RCM (HadAM3P) BL \#1-3"] and future ["RCM (HadAM3P) SRES A2 \#1-3"] simulations downscale the three parallel HadAM3P integrations, and the differences between the three RCM realizations from an ensemble reflect the "natural variability uncertainty".

The surface boundary conditions for "RCM (ERA40) BL" were derived from a combination of the monthly Hadley Centre Sea Ice and Sea Surface Temperature dataset (HadISST) and weekly NCEP observed datasets, 
while "RCM (HadAM3P) BL \#1-3" used the HadISST observed time series of SSTs and sea-ice. Note that HadISST is the Hadley Centre's global monthly SST and sea ice dataset, which has a $1^{\circ} \times 1^{\circ}$ latitude/longitude resolution and covers the period from 1870 to date (Rayner et al. 2003). For the future projections "RCM (HadAM3P) SRES A2 \#1-3", surface boundary conditions were obtained by adding changes in SSTs and sea-ice from the coupled atmosphere-ocean model HadCM3 to the HadISST observed time series. Compared to taking the surface

Table 1 PRECIS RCM simulations performed in this study

\begin{tabular}{|c|c|c|c|}
\hline \multirow[t]{3}{*}{ RCM simulations } & \multicolumn{3}{|l|}{ Boundary conditions } \\
\hline & \multicolumn{2}{|c|}{ Lateral (surface pressure, winds, temperature, humidity) } & \multirow[t]{2}{*}{ Surface (SST and sea-ice) } \\
\hline & Driving model & Emissions scenario & \\
\hline RCM (ERA40) BL & $\begin{array}{l}\text { ERA40, an ECMWF } \\
\text { reanalysis dataset }\end{array}$ & $\begin{array}{l}\text { Observed values of greenhouse gases; No } \\
\text { explicit representation of atmospheric } \\
\text { aerosols }\end{array}$ & $\begin{array}{l}\text { A combination of the monthly } \\
\text { HadISST and weekly NCEP } \\
\text { observed datasets }\end{array}$ \\
\hline $\begin{array}{l}\text { RCM (HadAM3P) BL \#1 } \\
\text { RCM (HadAM3P) BL \#2 } \\
\text { RCM (HadAM3P) BL \#3 }\end{array}$ & $\begin{array}{l}\text { The Hadley Centre's global } \\
\text { atmosphere-only model } \\
\text { HadAM3P }\end{array}$ & $\begin{array}{l}\text { Observed values of greenhouse gases; } \\
\text { Prescribed evolution of aerosols }\end{array}$ & The HadISST observed time series \\
\hline $\begin{array}{l}\text { RCM (HadAM3P) SRES } \\
\text { A2 \#1 } \\
\text { RCM (HadAM3P) SRES } \\
\text { A2 \#2 }\end{array}$ & \multirow[t]{3}{*}{ HadAM3P } & \multirow[t]{2}{*}{ SRES A2 } & \multirow[t]{3}{*}{$\begin{array}{l}\text { Combining changes in the HadCM3 } \\
\text { with the HadISST observed time } \\
\text { series }\end{array}$} \\
\hline $\begin{array}{l}\text { RCM (HadAM3P) SRES } \\
\text { A2 \#3 }\end{array}$ & & & \\
\hline $\begin{array}{l}\text { RCM (HadAM3P) SRES } \\
\text { B2 }\end{array}$ & & SRES B2 & \\
\hline
\end{tabular}

Fig. 2 PRECIS RCM domain over land divided into seven regions using EOF analysis and cluster analysis on simulated seasonal mean SAT and PREP from "RCM (ERA40) BL" in a winter and $\mathbf{b}$ summer seasons. c, d Same as (a) and (b), but denote the overlapping areas of the winter and summer clusters for the four northeastern US regions in gray. Subsequent analyses are performed separately for these four regions $(A, B, C$, and $D$ ) delimited by the thick black lines at $36.5^{\circ} \mathrm{N}$ and $49.5^{\circ} \mathrm{N}$ (a)

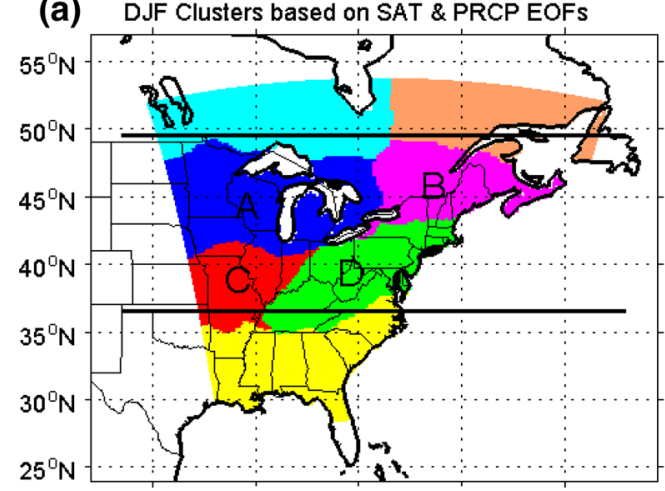

(c)

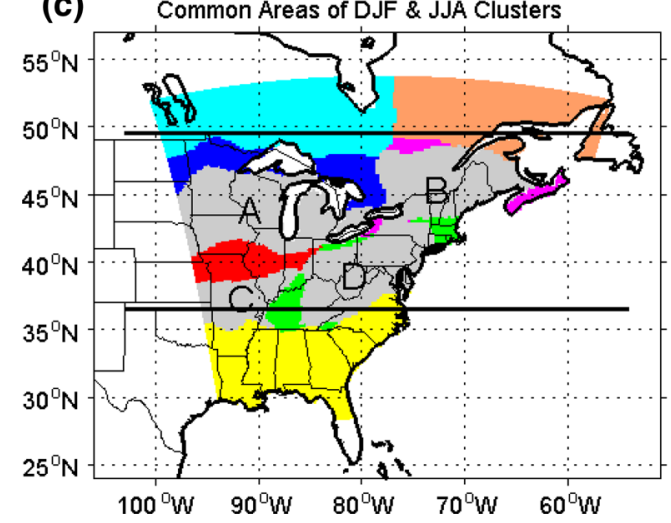

(b) JJA Clusters based on SAT \& PRCP EOFs

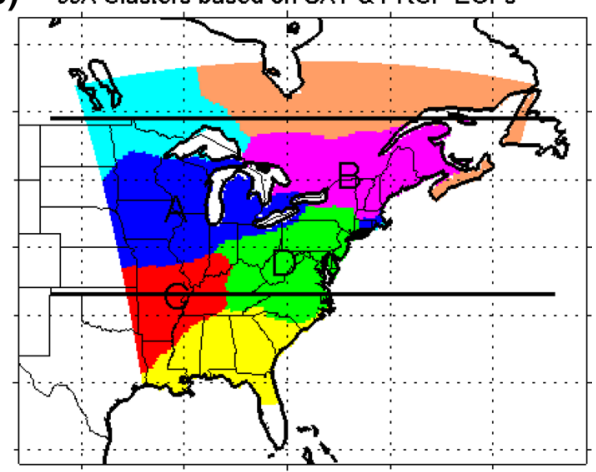

(d)

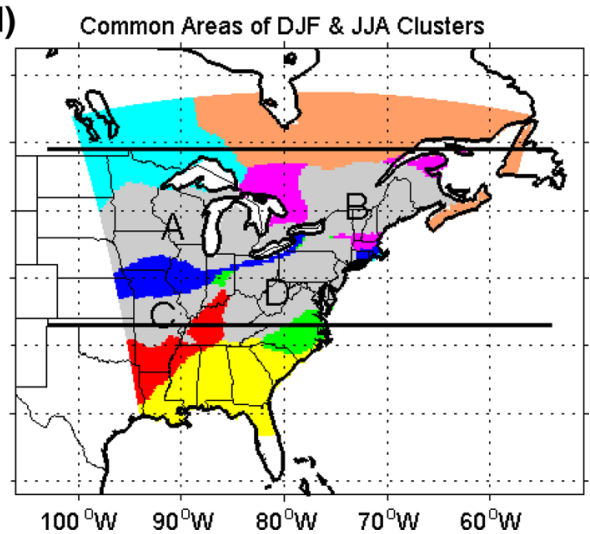


Fig. 3 Comparison of multiannual mean surface air temperature (SAT) for the winter season from a "RCM (ERA40) BL", b "RCM (HadAM3P) BL", c CRU data during the 1961-1990 period, and d NARR data during the 1980-1990 period. The RCM simulated SAT mean biases are shown relative to the CRU data in $\mathbf{e}$ and $\mathbf{f}$ for the 1961-1990 period and the NARR data in $\mathbf{g}$ and $\mathbf{h}$ for the 1980-1990 period. The results presented for "RCM (HadAM3P) BL" are based on the ensemble mean of three integrations
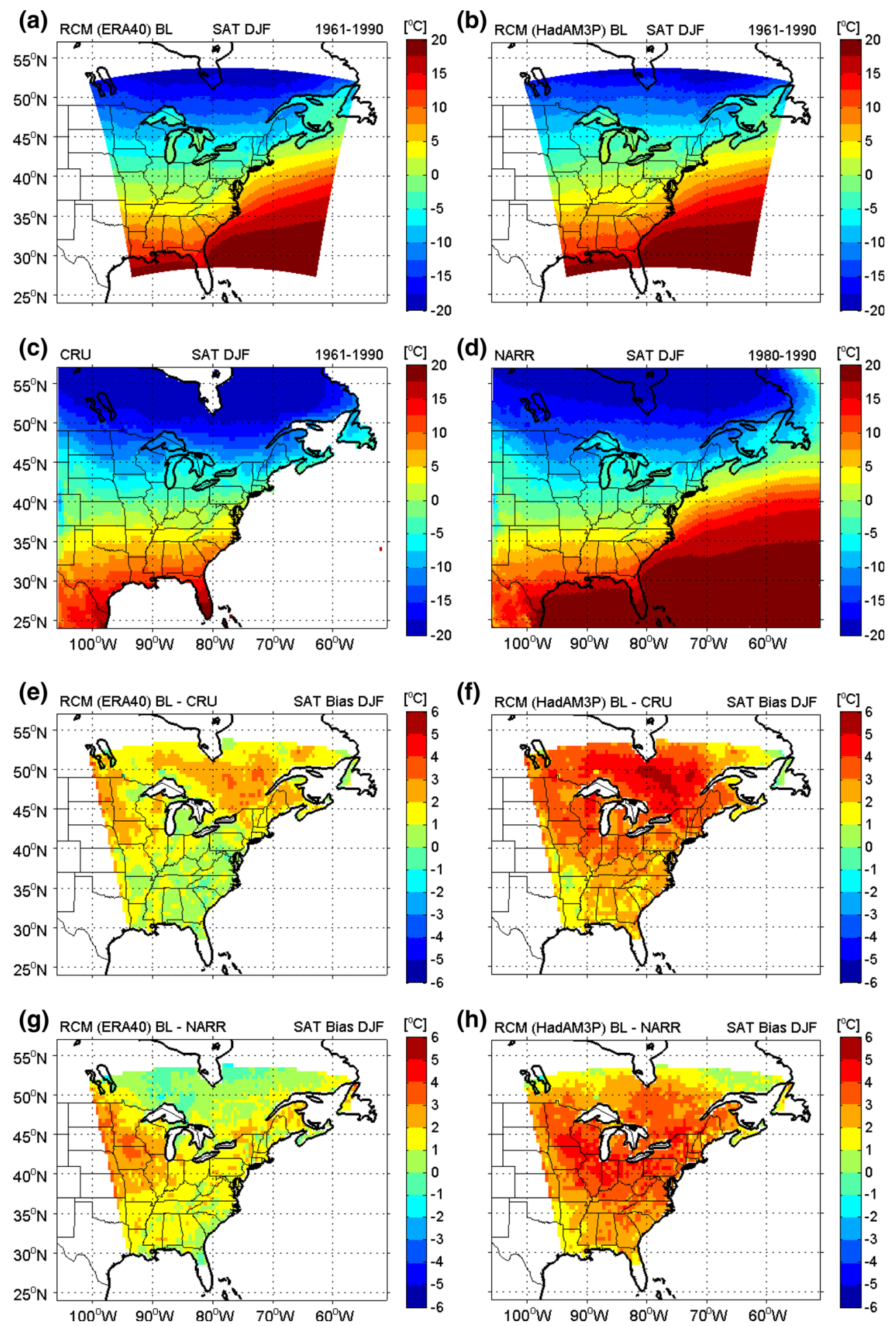

boundary information directly from the HadCM3, this method of combining coarse resolution GCM changes with higher resolution observed data could remove historical biases in the HadCM3 and provide corrected future surface boundary conditions (Rowell 2005).

All the baseline simulations use the observed values of greenhouse gas concentrations to provide relevant information on atmospheric composition. However, the representations of atmospheric aerosols are different when using different lateral boundary conditions. While there is no explicit representation of atmospheric aerosols in ERA40, the evolution of aerosol emissions are prescribed within the HadAM3P's sulphur cycle model component. In other words, when using lateral boundary conditions from 
Fig. 4 Comparison of multiannual mean surface air temperature (SAT) for the summer season from a "RCM (ERA40) BL", b "RCM (HadAM3P) BL", c CRU data during the 1961-1990 period, and d NARR data during the 1980-1990 period. The RCM simulated SAT mean biases are shown relative to the $\mathrm{CRU}$ data in $\mathbf{e}$ and $\mathbf{f}$ for the 1961-1990 period and the NARR data in $\mathbf{g}$ and $\mathbf{h}$ for the 1980-1990 period. The results presented for "RCM (HadAM3P) BL" are based on the ensemble mean of three integrations
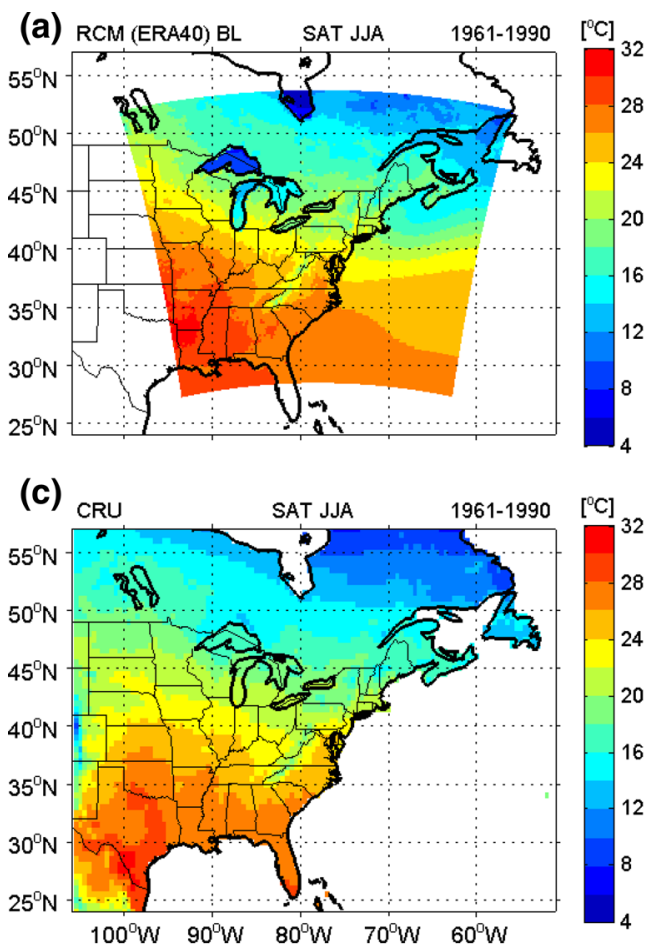

(e)
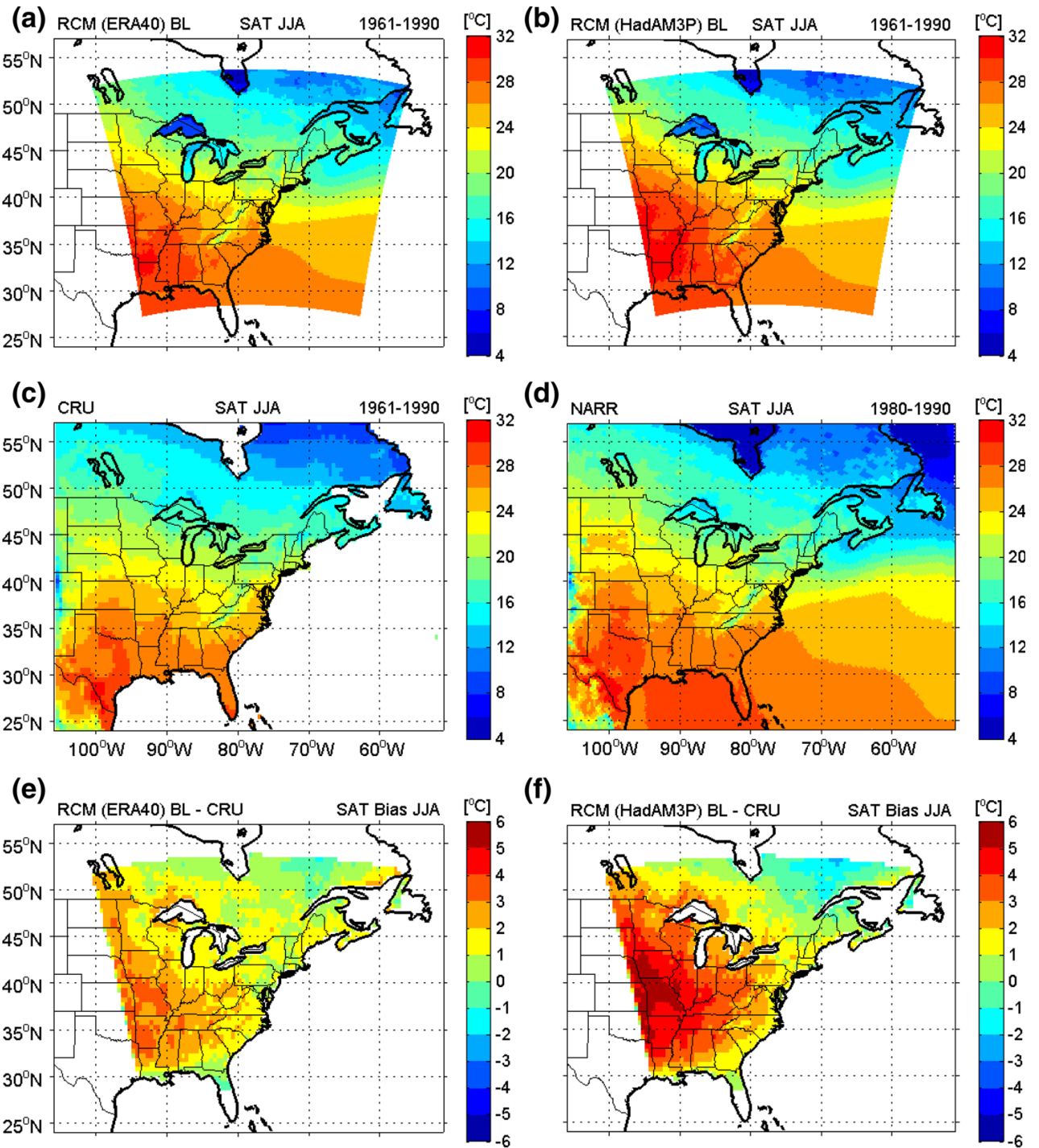

(d)

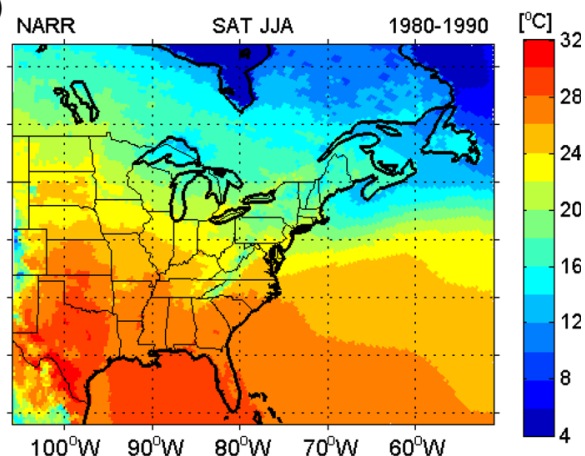

(f)
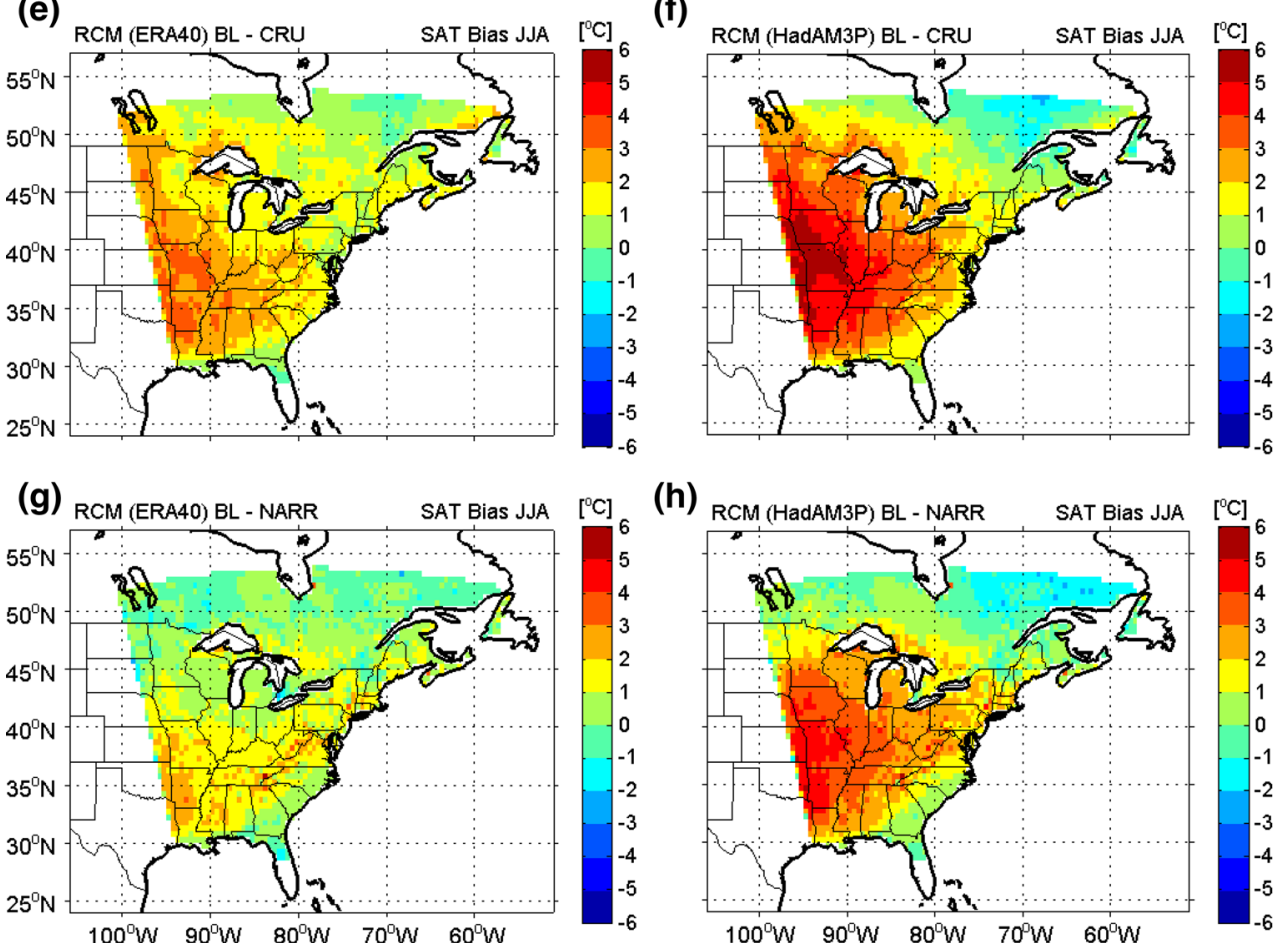

(h)

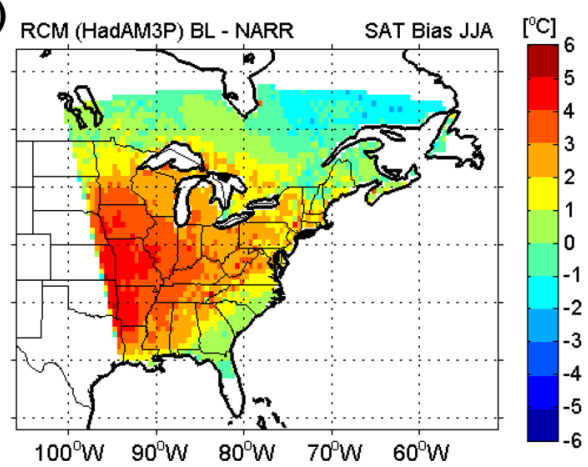

the HadAM3P, not only emissions from within the RCM domain are included as source terms, aerosols may also be advected into the domain via the lateral boundary conditions. The evolution of greenhouse gases and aerosols in the future projections are prescribed based on the "SRES scenarios" data (Nakićenović et al. 2000). Since how anthropogenic emissions will change in the future are uncertain and these "SRES scenarios" are equally plausible, running RCM simulations consistent with different emissions scenarios will help estimate the range of possible future climates. For the higher SRES A2 and lower SRES B2 scenarios used in this study, atmospheric concentrations 
Table 2 Comparison of observed and simulated multiannual mean surface air temperature (SAT) and total precipitation rate (PRCP) for winter and summer seasons over the four northeastern US regions during the current period

\begin{tabular}{|c|c|c|c|c|c|c|}
\hline & $\begin{array}{l}\text { CRU } 3.0 \\
(1961-1990)\end{array}$ & $\begin{array}{l}\text { NARR } \\
(1980-1990)\end{array}$ & $\begin{array}{l}\text { ERA40 } \\
(1961-1990)\end{array}$ & $\begin{array}{l}\text { RCM (ERA40) BL } \\
(1961-1990)\end{array}$ & $\begin{array}{l}\text { HadAM3P } \\
(1961-1990)\end{array}$ & $\begin{array}{l}\text { RCM (HadAM3P) } \\
\text { BL (1961-1990) }\end{array}$ \\
\hline \multicolumn{7}{|c|}{ SAT $\left({ }^{\circ} \mathrm{C}\right)$ region $\mathrm{A}$} \\
\hline Winter (DJF) & -8.94 & -8.50 & -8.15 & -7.35 & -7.44 & -5.57 \\
\hline Summer (JJA) & 21.13 & 21.92 & 21.30 & 23.17 & 23.45 & 24.90 \\
\hline \multicolumn{7}{|c|}{ SAT $\left({ }^{\circ} \mathrm{C}\right)$ region $\mathrm{B}$} \\
\hline Winter (DJF) & -10.32 & -8.96 & -8.77 & -8.15 & -7.57 & -6.57 \\
\hline Summer (JJA) & 16.85 & 17.09 & 17.49 & 17.89 & 16.62 & 17.75 \\
\hline \multicolumn{7}{|c|}{ SAT $\left({ }^{\circ} \mathrm{C}\right)$ region $\mathrm{C}$} \\
\hline Winter (DJF) & -1.20 & -1.51 & -1.03 & 0.10 & 0.21 & 1.29 \\
\hline Summer (JJA) & 24.64 & 25.31 & 24.65 & 27.49 & 28.39 & 29.38 \\
\hline \multicolumn{7}{|c|}{ SAT $\left({ }^{\circ} \mathrm{C}\right)$ region $\mathrm{D}$} \\
\hline Winter (DJF) & -1.18 & -1.18 & -0.56 & -0.29 & 0.62 & 1.66 \\
\hline Summer (JJA) & 21.77 & 21.94 & 22.03 & 23.37 & 23.08 & 24.31 \\
\hline \multicolumn{7}{|c|}{$\mathrm{PRCP}\left(\mathrm{mm} \mathrm{day}{ }^{-1}\right)$ region A } \\
\hline Winter (DJF) & 1.13 & 0.80 & 1.27 & 1.49 & 2.10 & 1.78 \\
\hline Summer (JJA) & 3.10 & 2.99 & 2.23 & 2.62 & 2.37 & 2.18 \\
\hline \multicolumn{7}{|c|}{$\mathrm{PRCP}\left(\mathrm{mm} \mathrm{day}^{-1}\right)$ region $\mathrm{B}$} \\
\hline Winter (DJF) & 2.64 & 1.21 & 2.37 & 2.84 & 3.05 & 2.81 \\
\hline Summer (JJA) & 3.19 & 2.74 & 2.52 & 3.09 & 2.77 & 2.77 \\
\hline \multicolumn{7}{|c|}{$\mathrm{PRCP}\left(\mathrm{mm}\right.$ day $\left.^{-1}\right)$ region $\mathrm{C}$} \\
\hline Winter (DJF) & 1.57 & 1.68 & 1.37 & 1.64 & 3.01 & 2.57 \\
\hline Summer (JJA) & 3.17 & 3.05 & 2.65 & 2.53 & 2.06 & 1.97 \\
\hline \multicolumn{7}{|c|}{$\mathrm{PRCP}\left(\mathrm{mm} \mathrm{day}^{-1}\right)$ region $\mathrm{D}$} \\
\hline Winter (DJF) & 2.48 & 2.21 & 2.22 & 3.02 & 3.94 & 3.74 \\
\hline Summer (JJA) & 3.30 & 3.11 & 2.81 & 3.39 & 2.81 & 2.89 \\
\hline
\end{tabular}

of carbon dioxide $\left(\mathrm{CO}_{2}\right)$ will rise to approximately 850 and $620 \mathrm{ppm}$ by 2,100 , respectively.

It is worth noting that in the following analysis, a 1-year spin-up period for the soil variables in the land-surface model to come into equilibrium with the atmospheric forcing and 8-point buffer zone where the RCM values are relaxed towards the driving boundary data have been eliminated. The results related to the RCM simulations driven by the HadAM3P (i.e., "RCM (HadAM3P) BL" and "RCM (HadAM3P) SRES A2") are presented as the ensemble average of the three ensemble members.

\subsection{Regionalization}

Due to wide-ranging characteristics of the mean and variability of climatic variables across the northeastern United States, it is useful to divide the relatively large RCM domain into several climatologically similar regions. Following the strategy developed by Karmalkar et al. (2011), we divided the land area of the domain in terms of surface air temperature (SAT) and total precipitation rate (PRCP).
This approach employs a combination of empirical orthogonal functions (EOF) analysis to isolate characteristic patterns of variability and K-means cluster analysis to partition the land points into clusters. First of all, we performed the EOF analysis on seasonal mean SAT and PRCP fields simulated by "RCM (ERA40) BL" for winter (DJF) and summer (JJA) seasons separately (Figs. S1-S4 in the online supplement). The PRCP fields were smoothed (i.e., spatially averaged over blocks of 49 grid points) before the EOF analysis to reduce the impact of small-scale spatial features. The first three SAT and first four PRCP EOF spatial patterns, which explain more than 80 and $50 \%$ of the total variance, were retained and put into the K-means clustering algorithm to divide the RCM domain over land into seven regions (Fig. 2a, b).

The northeastern US region of interest was divided into four sub-divisions (A, B, C and D in Fig. 2a, b) for both winter and summer seasons. Although the divisions are slightly different between the two seasons, the large overlapping areas (Fig. 2c, d) indicate their common features. Despite the arbitrariness in the choice of the number 
Fig. 5 Comparison of multiannual mean total precipitation rate $(\mathrm{PRCP})$ for the winter season from a "RCM (ERA40) BL", b "RCM (HadAM3P) BL", c CRU data during the 1961-1990 period, and $\mathbf{d}$ NARR data during the 1980-1990 period. The RCM simulated PRCP mean biases are shown relative to the CRU data in $\mathbf{e}$ and $\mathbf{f}$ for the 1961-1990 period. The results presented for "RCM

(HadAM3P) BL" are based on the ensemble mean of three integrations

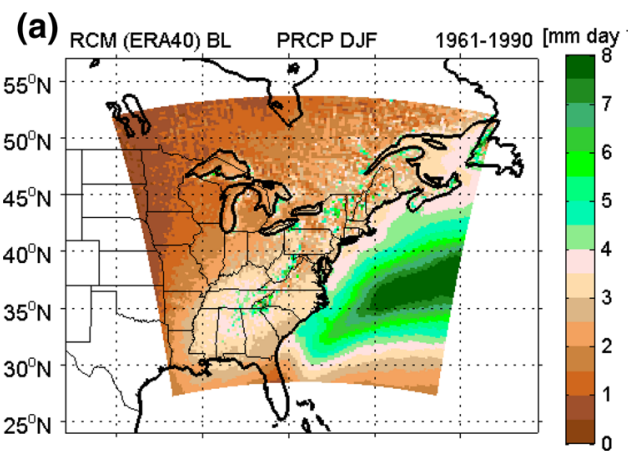

(b)
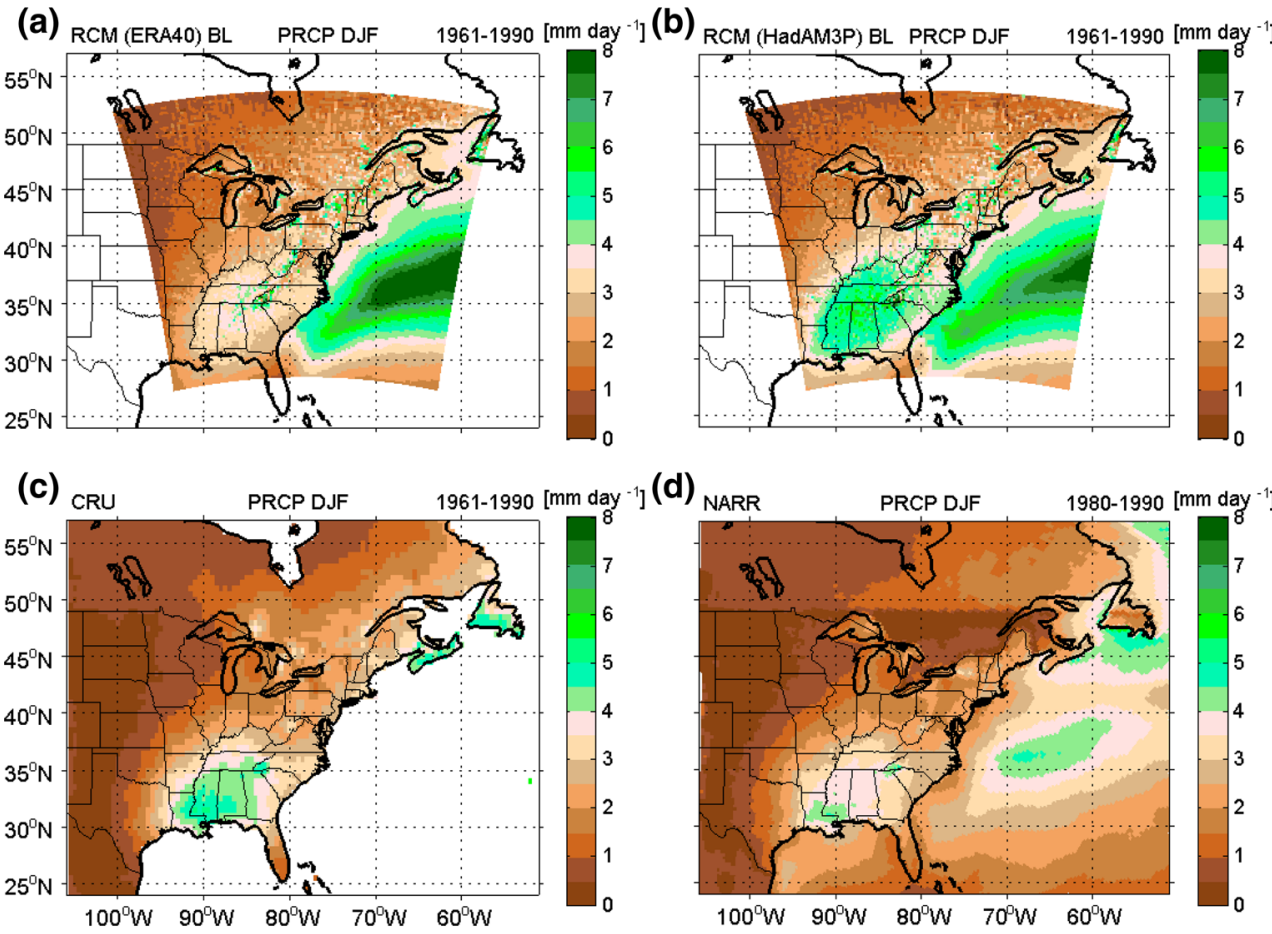

(d)

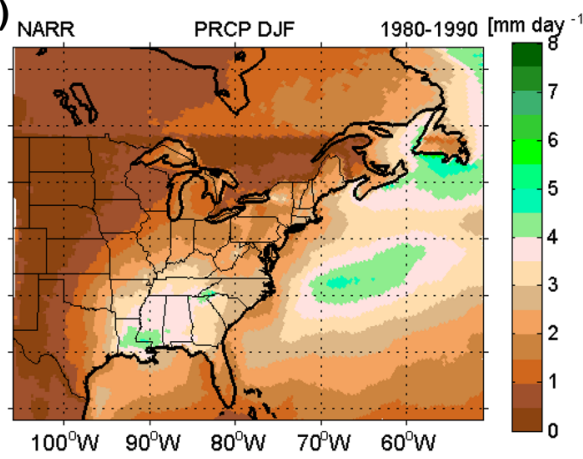

(e)

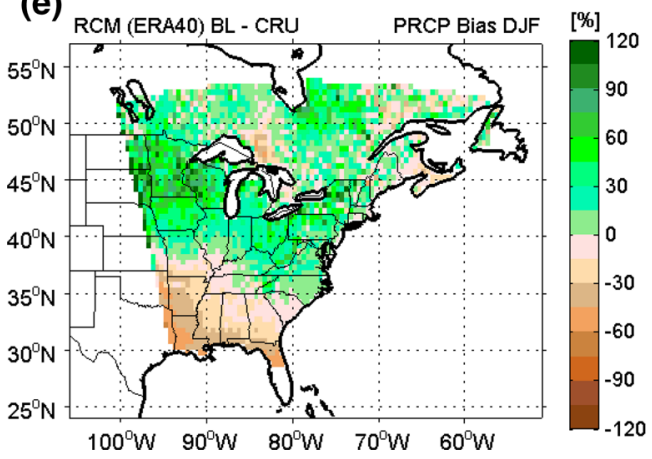

(f)

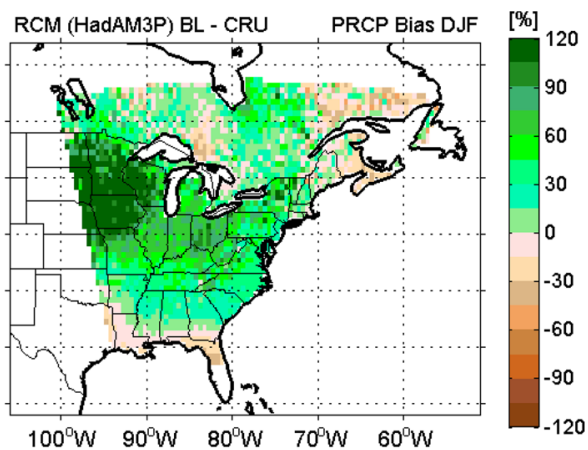

of clusters, the division distinguishes relatively cold and dry (Region A), cold and wet (Region B), warm and dry (Region C), and warm and wet (Region D) climatic regions, and these sub-divisions were subsequently used to examine climate changes across the larger region.

\section{Model validation}

\subsection{Multiannual mean}

As temperature and precipitation are two primary climate indicators, it is crucial to first examine the extent to which the RCM baseline simulations are able to reproduce observed characteristics of these two indicators. Comparison of multiannual mean SAT from the RCM baseline simulations and the observed data are shown in Figs. 3 and 4 for the winter and summer seasons, respectively. The
RCM simulations reproduce well the large-scale spatial structure of the mean SAT field, as represented by the CRU data and the NARR data. In comparison with the CRU data, the RCM simulations overestimate the SAT, especially for the northern regions in winter and western regions in summer. The significant winter warm biases in both "RCM (ERA40) BL" and "RCM (HadAM3P) BL" over the northern part of the domain relative to the CRU data may be attributed to the differences in the modeled and observed snow-ice albedo feedbacks. Moreover, more pronounced winter warm biases in "RCM (HadAM3P) BL" could be a reflection of the driving HadAM3P biases.

The quantified values of the observed and simulated SAT and PRCP over the four northeastern US regions during the current period are compared in Table 2. The overestimation of the mean SAT is more prominent in "RCM (HadAM3P) BL" than in "RCM (ERA40) BL", which may be attributable to large warm biases in the 
Fig. 6 Comparison of multiannual mean total precipitation rate (PRCP) for the summer season from a "RCM (ERA40) BL", b "RCM (HadAM3P) BL", c CRU data during the 1961-1990 period, and $\mathbf{d}$ NARR data during the 1980-1990 period. The RCM simulated PRCP mean biases are shown relative to the CRU data in $\mathbf{e}$ and $\mathbf{f}$ for the 1961-1990 period. The results presented for "RCM (HadAM3P) BL" are based on the ensemble mean of three integrations
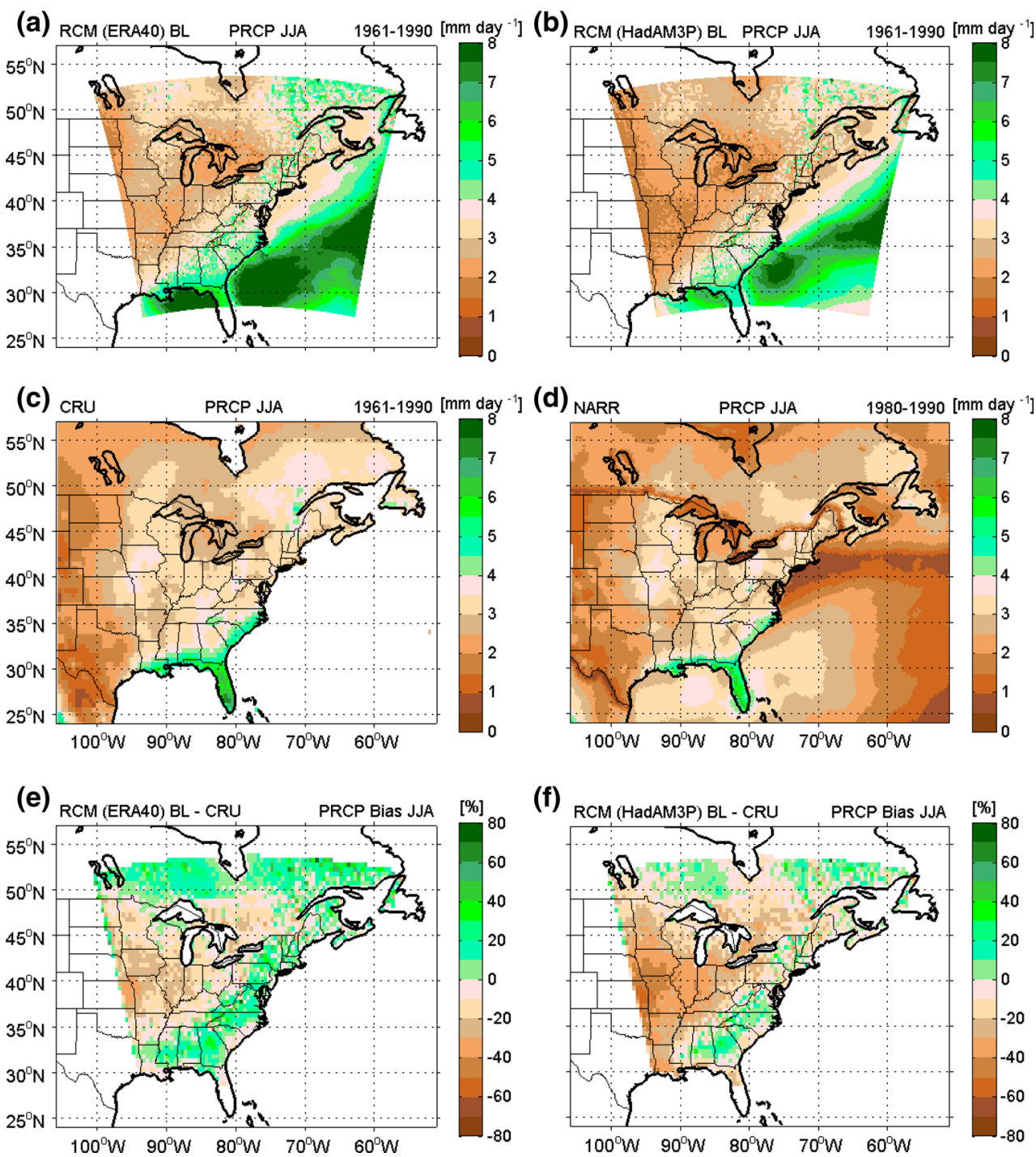

driving HadAM3P. Though the RCM can freely generate its own features on smaller temporal and spatial scales, the large-scale RCM circulation can not diverge from its driving GCM. Consequently, relatively strong overestimation of SAT in HadAM3P (Table 2), especially in region $\mathrm{B}$ during winter $\left(+2.75{ }^{\circ} \mathrm{C}\right)$ and region $\mathrm{C}$ during summer $\left(+3.75^{\circ} \mathrm{C}\right)$, is partly responsible for the relatively large warm biases in "RCM (HadAM3P) BL". Further, the RCM simulations exhibit stronger overestimation of the mean SAT than their driving HadAM3P.

The simulated and observed multiannual mean PRCP and biases relative to the CRU data for winter and summer seasons are illustrated in Figs. 5 and 6. The spatial patterns of the precipitation climatology biases relative to the NARR data are not presented due to some deficiencies in this reanalysis product (Bukovsky and Karoly 2007). For instance, there is an apparent precipitation discontinuity along the United States-Canada and United States-Mexico borders during the summer season (Fig. 6d), which arises from the different precipitation observations used to produce the NARR archive. The precipitation climatology over Canada during the winter season also seems to be unrealistic (Fig. 5d). In addition, while the NARR reproduces precipitation over the continental United States reasonably well, it does not provide reliable precipitation data over the northern oceans. This is attributed to the fact that the full precipitation assimilation of the CMAP (Climate Prediction Center's Merged Analysis of Precipitation) data (Xie and Arkin 1997) is only available over the oceans south of $27.5^{\circ} \mathrm{N}$ (Mesinger et al. 2006). Some inaccuracies in the NARR precipitation mentioned above (e.g., winter precipitation minima in Canada, and the summer precipitation discontinuity over the United States-Canada boundaries) are also reflected in the multiannual mean precipitation comparison between the NARR and CRU data (Fig. S5 in the online supplement). For most parts of 
Fig. 7 Probability density functions (PDFs) of monthly SAT in $\mathbf{a}$ winter and $\mathbf{b}$ summer seasons for the CRU data (black), "RCM (ERA40) BL" (dashed black), "RCM

(HadAM3P) BL" (thin color), "RCM (HadAM3P) SRES B2" (dashed thick color), and "RCM (HadAM3P) SRES A2" (thick color) in the four northeastern US regions defined in Fig. 2.

Vertical lines denote the means of respective distributions. The fitted Gaussian distributions are plotted, and the results presented for "RCM

(HadAM3P) BL" and "RCM (HadAM3P) SRES A2" are based on the ensemble mean of three integrations

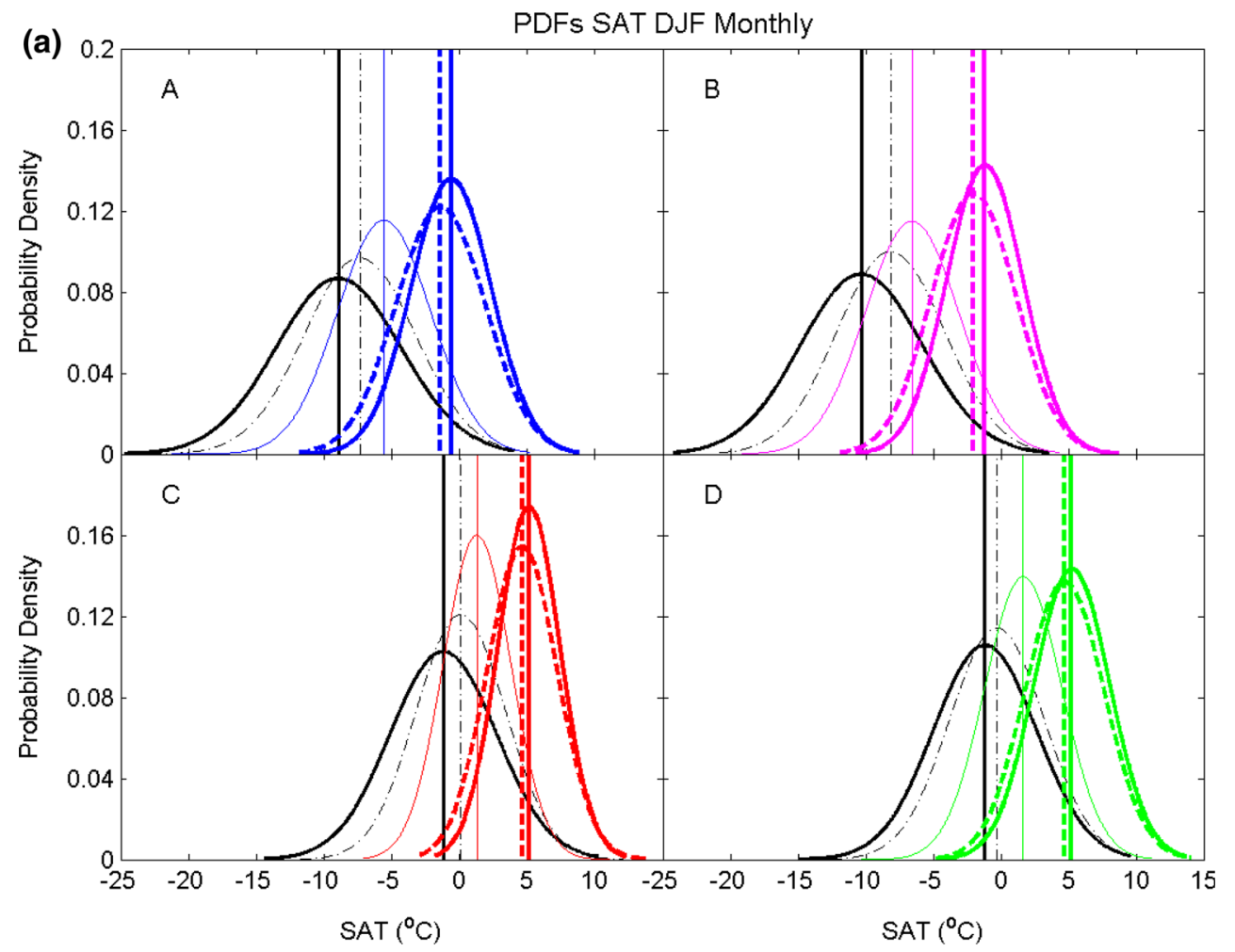

(b)

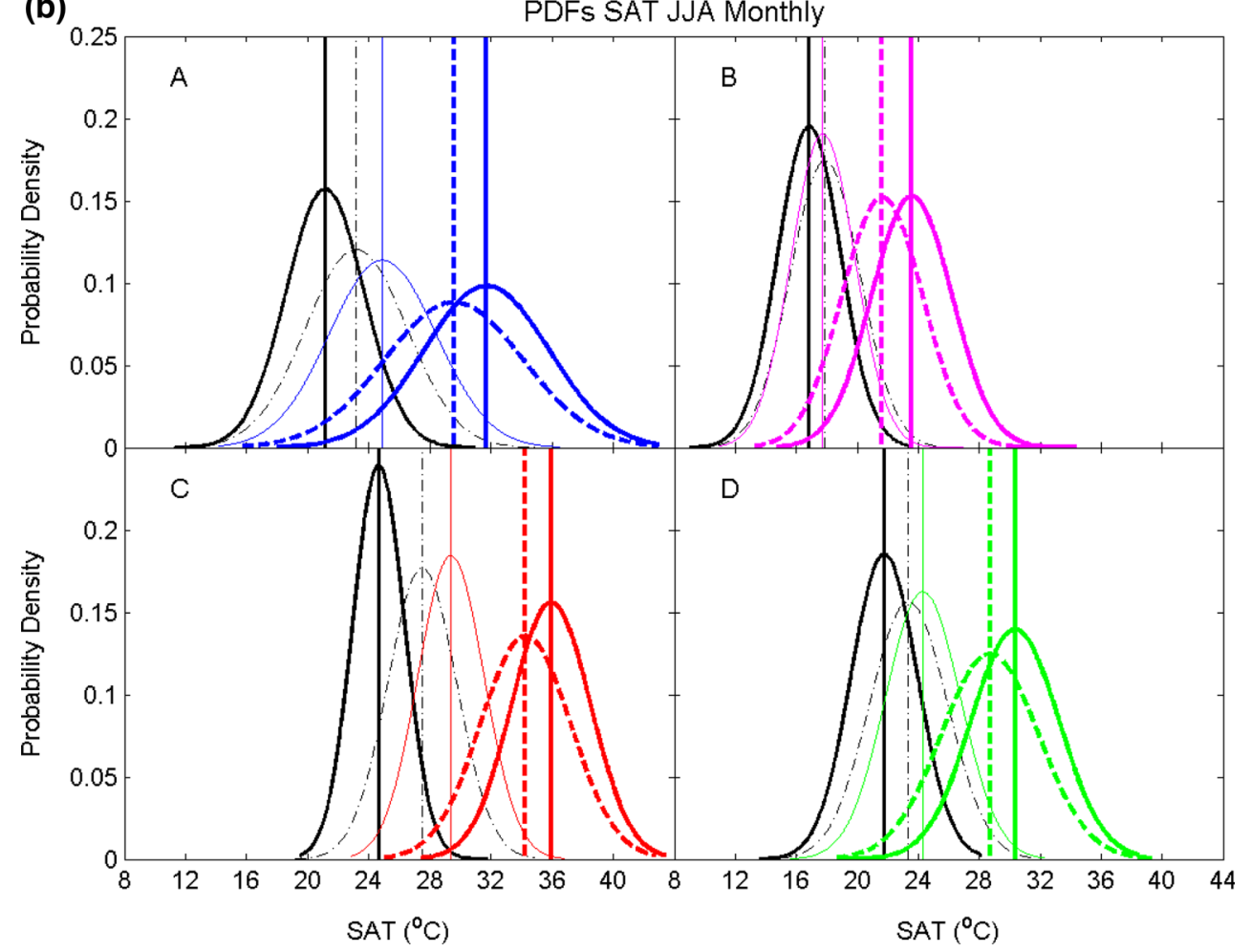

the northeastern US, the RCM baseline simulations tend to overestimate PRCP in winter but underestimate PRCP in summer. The largest overestimation (expressed as percentage bias) of winter precipitation by "RCM
(HadAM3P) BL" is seen in the northwestern part of the domain, which receives the lowest winter precipitation in the present-day period (Table 2). Comparing the summer PRCP biases (Fig. 6e, f) with the summer SAT biases 
(Fig. 4e, f), it is evident that the underestimation of summer precipitation over the western and central parts of the domain coincides with the overestimation of summer SAT. A plausible explanation is that less precipitation is associated with less evaporation and higher surface temperature, which leads to positive sensible heat flux biases from the surface and consequently warm SAT biases.

\subsection{Probability density functions}

For the purpose of examining the temporal and spatial distributions, we used probability density functions (PDFs) to describe the monthly mean SAT and PRCP distributions during winter and summer over the 30-year period across each of the four northeastern US regions. The monthly means of SAT may be assumed to come from the Gaussian distribution written as

$f(x \mid \mu, \sigma)=\frac{1}{\sigma \sqrt{2 \pi}} e^{-\frac{1}{2}\left(\frac{x-\mu}{\sigma}\right)^{2}}$,

where $\mu$ and $\sigma$ are the mean and standard deviation. The comparisons between the SAT distributions from original data and their PDFs in "RCM (ERA40) BL" indicate that monthly SAT distributions over every northeastern US region conform to a Gaussian distribution (Fig. S6 in the online supplement). Figure 7 shows the Gaussian distributions of the observed and simulated monthly mean SAT from the thirty-year data for all the grid points within every region during winter and summer seasons, respectively. The RCM biases of the SAT mean and variability in comparison with the CRU data are tabulated in Table 3. The means of the SAT distributions are greater in the RCM baseline simulations than in the CRU observations, especially for region $\mathrm{B}$ in winter and region $\mathrm{C}$ in summer. The mean biases are relatively small in the southern part of the domain (regions $\mathrm{C}$ and D) for winter and in the eastern part (regions B and D) for summer. While the widths of the RCM simulated SAT distributions are narrower than those of the observed distributions during the winter, the case is exactly opposite for the summer season. In general, "RCM (ERA40) BL" shows smaller SAT mean and variability biases than "RCM (HadAM3P) BL", indicating that better simulation results are obtained by using quasi-observed driving data. For those regions with relatively large SAT mean biases (i.e., northern regions in winter and western regions in summer), the warm biases in "RCM (ERA40) BL" are at least $1.5^{\circ} \mathrm{C}$ smaller than that in "RCM (HadAM3P) BL".

We also present the Gaussian distributions of monthly SAT for the three baseline simulations ["RCM (HadAM3P) BL \#1 3"] and three SRES A2 simulations ["RCM (HadAM3P) SRES A2 \#1 3"] to estimate the "natural variability uncertainty" (Fig. S8 in the online supplement). The differences in the mean and variability of monthly SAT between the three ensemble realizations are quantified (Table S1 in the online supplement). The PDFs of SAT distributions for the three baseline ensemble simulations have very close means and similar shapes and widths. The differences in the means of SAT PDFs between different baseline realizations from an ensemble are only of the order $10^{-2}$ or $10^{-1}{ }^{\circ} \mathrm{C}$, far smaller than the differences between the baseline simulations driven by different boundary data.

The monthly means of PRCP follow the gamma distribution, which can be expressed in terms of the gamma function and two parameters as

$f(x \mid k, \theta)=\frac{1}{\theta^{k} \Gamma(k)} x^{k-1} e^{-\frac{x}{\theta}}$,

where $k$ and $\theta$ denote shape and scale parameter, respectively. The comparisons between the PRCP distributions from original data and their PDFs in "RCM (ERA40) BL" suggest that a gamma distribution is an appropriate fit to monthly precipitation data (Fig. S7 in the online supplement). The gamma distributions of the observed and simulated monthly mean PRCP are illustrated in Fig. 8 and the PRCP biases are tabulated in Table 4 . The relatively large absolute mean biases of precipitation are in the southern regions (regions $\mathrm{C}$ and $\mathrm{D}$ ) during the winter and in the western regions (regions $\mathrm{A}$ and $\mathrm{C}$ ) during the summer. It is important to note that a small absolute bias may be associated with a large percentage bias due to the small amounts of precipitation received in the dry regions. As it is illustrated in Tables 2 and 4, though the absolute wet bias for Region A $\left(0.65 \mathrm{~mm} \mathrm{day}^{-1}\right)$ during the winter is only half of the bias for region $\mathrm{D}\left(1.26 \mathrm{~mm} \mathrm{day}^{-1}\right)$ in

Table 3 The RCM simulations biases in the mean $(\mu)$ and standard deviation $(\sigma)$ of monthly SAT relative to the CRU data for the four northeastern US regions during the 1961-1990 period

\begin{tabular}{|c|c|c|c|c|}
\hline & \multicolumn{2}{|l|}{$\mu_{\text {bias }}\left({ }^{\circ} \mathrm{C}\right)$} & \multicolumn{2}{|l|}{$\sigma_{\text {bias }}(\%)$} \\
\hline & $\begin{array}{l}\text { RCM } \\
\text { (ERA40) }\end{array}$ & $\begin{array}{l}\text { RCM } \\
\text { (HadAM3P) }\end{array}$ & $\begin{array}{l}\text { RCM } \\
\text { (ERA40) }\end{array}$ & $\begin{array}{l}\text { RCM } \\
\text { (HadAM3P) }\end{array}$ \\
\hline \multicolumn{5}{|c|}{ Winter season (DJF) } \\
\hline Region A & 1.59 & 3.37 & -10.6 & -15.2 \\
\hline Region B & 2.17 & 3.75 & -11.2 & -13.1 \\
\hline Region C & 1.30 & 2.49 & -15.2 & -23.1 \\
\hline Region D & 0.89 & 2.84 & -7.6 & -11.7 \\
\hline \multicolumn{5}{|c|}{ Summer season (JJA) } \\
\hline Region A & 2.04 & 3.76 & 30.3 & 53.4 \\
\hline Region B & 1.05 & 0.90 & 11.7 & 17.7 \\
\hline Region C & 2.85 & 4.73 & 35.0 & 62.4 \\
\hline Region D & 1.60 & 2.54 & 18.4 & 28.0 \\
\hline
\end{tabular}


Fig. 8 Probability density functions (PDFs) of monthly $\mathrm{PRCP}$ in $\mathbf{a}$ winter and $\mathbf{b}$ summer seasons for the CRU data (black), "RCM (ERA40) BL" (dashed black), "RCM

(HadAM3P) BL" (thin color), "RCM (HadAM3P) SRES B2" (dashed thick color), and "RCM (HadAM3P) SRES A2" (thick color) in the four northeastern US regions defined in Fig. 2. Vertical lines denote the means of respective distributions. The fitted gamma distributions are plotted, and the results presented for "RCM

(HadAM3P) BL" and "RCM (HadAM3P) SRES A2" are based on the ensemble mean of three integrations

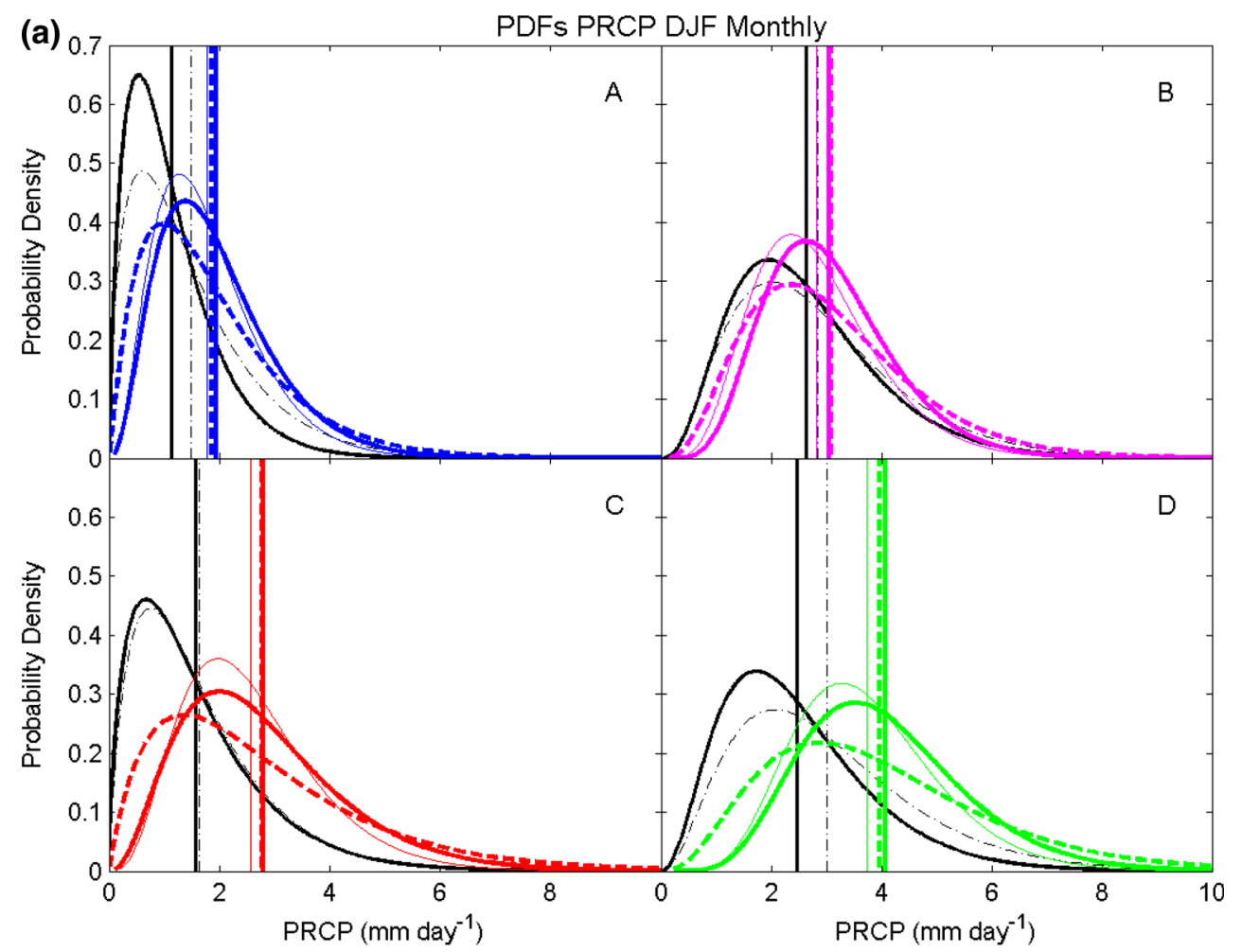

(b)

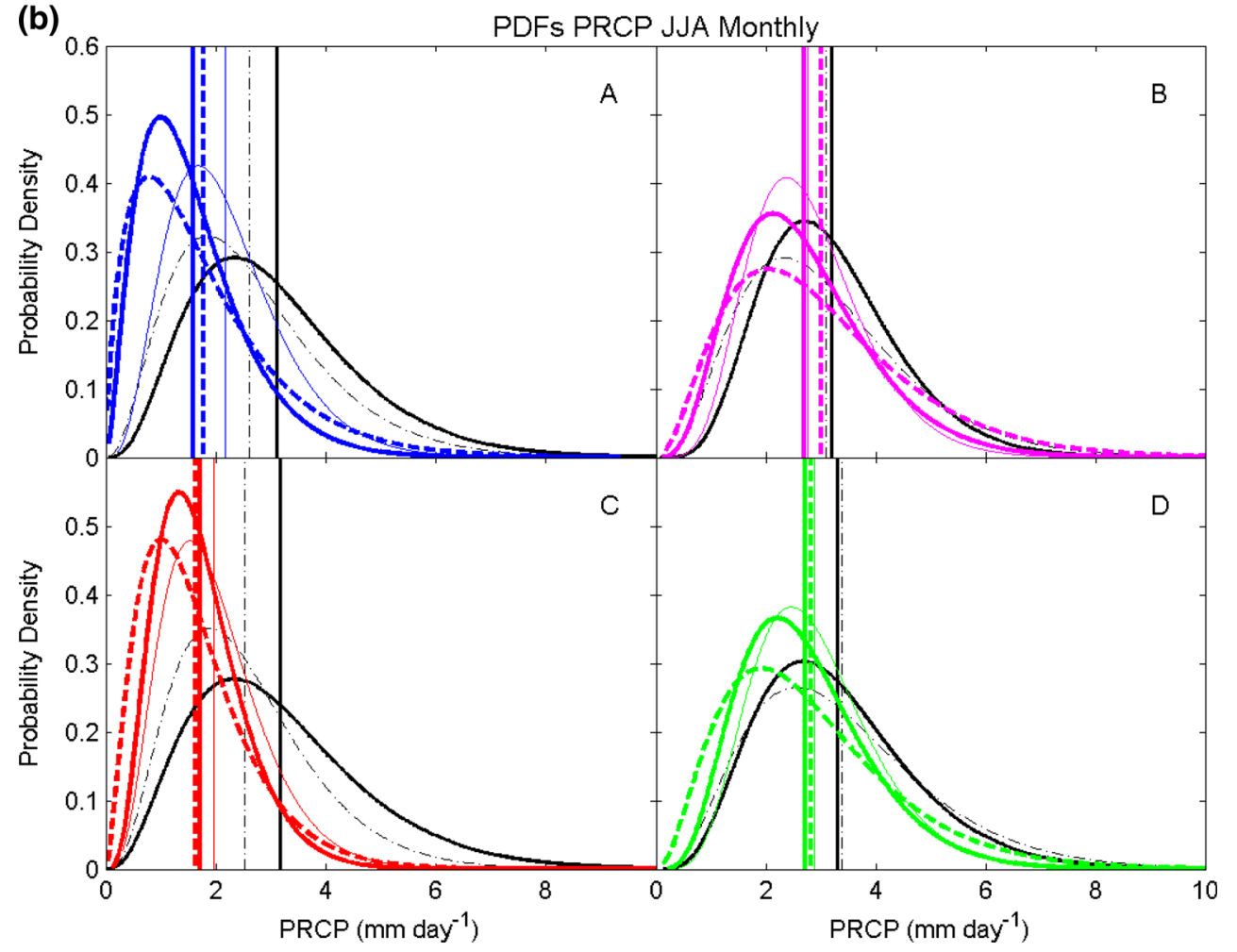

"RCM (HadAM3P) BL", the percentage biases in these two regions are comparable (58.3 vs. $51.2 \%$ ). During the winter season, the PRCP variability biases are positive for all four regions. For summer, the wetter regions (regions B and D) have positive variability biases and the drier regions (regions $\mathrm{A}$ and $\mathrm{C}$ ) have negative variability biases. 


\section{Response to climate change}

\subsection{Surface air temperature response}

The projected future changes in the multiannual mean SAT are shown in Fig. 9. There is an overall warming for the whole RCM domain under both SRES A2 and SRES B2 scenarios for both winter and summer seasons, except for a small region over the northeast coast during the summer. According to a Student $t$ test, the warming is statistically

Table 4 The RCM simulations biases in the mean $(\mu)$ and standard deviation $(\sigma)$ of monthly PRCP relative to the CRU data for the four northeastern US regions during the 1961-1990 period

\begin{tabular}{|c|c|c|c|c|}
\hline & \multicolumn{2}{|l|}{$\mu_{\text {bias }}(\%)$} & \multicolumn{2}{|l|}{$\sigma_{\text {bias }}(\%)$} \\
\hline & $\begin{array}{l}\text { RCM } \\
\text { (ERA40) }\end{array}$ & $\begin{array}{l}\text { RCM } \\
\text { (HadAM3P) }\end{array}$ & $\begin{array}{l}\text { RCM } \\
\text { (ERA40) }\end{array}$ & $\begin{array}{l}\text { RCM } \\
\text { (HadAM3P) }\end{array}$ \\
\hline \multicolumn{5}{|c|}{ Winter season (DJF) } \\
\hline Region A & 32.1 & 58.3 & 28.7 & 37.2 \\
\hline Region B & 7.6 & 6.6 & 16.2 & 11.8 \\
\hline Region C & 4.0 & 63.1 & 0.9 & 51.1 \\
\hline Region D & 21.7 & 51.2 & 25.2 & 45.8 \\
\hline \multicolumn{5}{|c|}{ Summer season (JJA) } \\
\hline Region A & -15.5 & -29.7 & -3.5 & -0.4 \\
\hline Region B & -3.0 & -13.1 & 29.4 & 21.9 \\
\hline Region C & -20.0 & -37.9 & -16.8 & -12.3 \\
\hline Region D & 2.8 & -12.4 & 26.5 & 23.5 \\
\hline
\end{tabular}

significant ( $p<0.001$ for a one-sided test), indicating the robustness in the future increase in SAT.

The projected future distributions of monthly SAT and the quantified changes in their mean and variability over the four northeastern US regions are presented (Fig. 7; Table 5). The future changes in the multiannual mean SAT during the winter season under the higher emissions scenario (SRES A2) are 4.95, 5.39, 3.83, and $3.59{ }^{\circ} \mathrm{C}$ in the four regions, respectively. Compared with the winter warming $\left(3.59-5.39^{\circ} \mathrm{C}\right)$, the RCM projects an even larger increase in summer mean SAT $\left(5.83-6.81{ }^{\circ} \mathrm{C}\right)$ under the SRES A2 scenario. Under the lower emissions scenario (SRES B2), summer warming is also larger than winter warming except for region $\mathrm{B}$. The end-of-century temperature increase over the northeastern region (B) projected by this PRECIS RCM is larger than that based on the ensemble average from 9 AOGCMs (Hayhoe et al. 2007), which projects $3.7^{\circ} \mathrm{C}$ winter warming and $4.3{ }^{\circ} \mathrm{C}$ summer warming by 2070-2099 relative to 1961-1990 under the SRES A2 scenario. But the projected warming by this PRECIS RCM is within the range of temperature projections from individual AOGCM simulations. It is interesting to note that the projected increase in the mean SAT during the winter is insensitive to the emissions scenario uncertainty. The differences in the winter mean SAT between the two emissions scenarios, which are less than $0.9^{\circ} \mathrm{C}$ for the four regions, are comparable to those between different realizations from the future SRES A2 ensemble (Fig. S8
Fig. 9 Projected future changes in the multiannual mean SAT under the SRES A2 (a, c) and SRES B2 (b, d) scenarios during winter $(\mathbf{a}, \mathbf{b})$ and summer (c, d) seasons. The future warming is statistically significant ( $p<0.001$ for a onesided test) for almost all the grid points in the domain. The results presented are the differences between the ensemble averaged future and current integrations
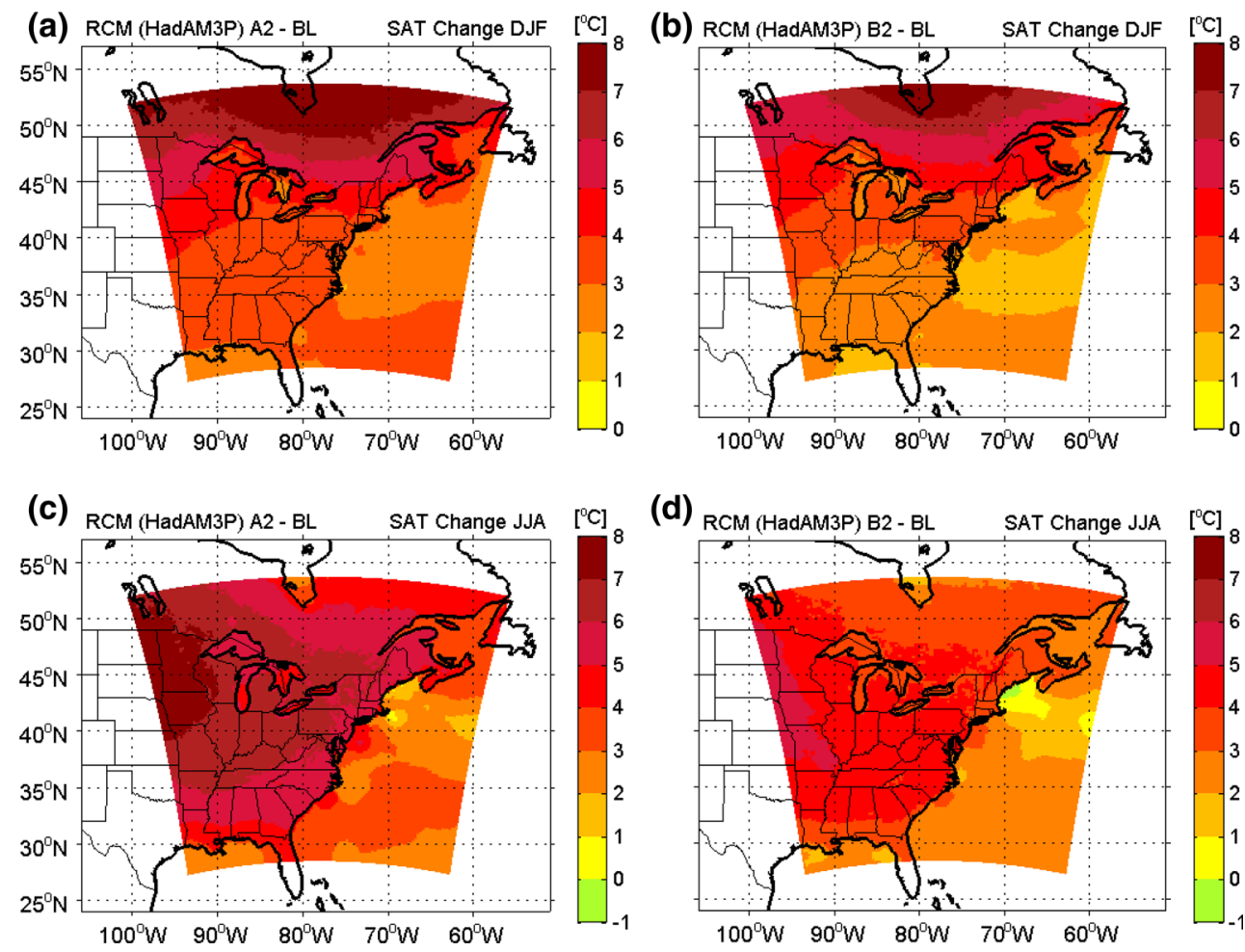
Table 5 Projected changes in the mean $(\mu)$ and standard deviation $(\sigma)$ of monthly SAT and PRCP under the SRES A2 and SRES B2 emissions scenarios for the four northeastern US regions
Changes are calculated based on the differences or percentage differences between "RCM (HadAM3P) SRES A2" ["RCM (HadAM3P) SRES B2"] and "RCM (HadAM3P) BL"

\begin{tabular}{|c|c|c|c|c|c|c|c|c|}
\hline \multirow{4}{*}{$\begin{array}{l}\text { Surface air temperature } \\
\text { (SAT) }\end{array}$} & \multicolumn{4}{|c|}{ Winter season (DJF) } & \multicolumn{4}{|c|}{ Summer season (JJA) } \\
\hline & \multicolumn{2}{|c|}{$\mu_{\text {change }}\left({ }^{\circ} \mathrm{C}\right)$} & \multicolumn{2}{|c|}{$\sigma_{\text {change }}(\%)$} & \multicolumn{2}{|c|}{$\mu_{\text {change }}\left({ }^{\circ} \mathrm{C}\right)$} & \multicolumn{2}{|c|}{$\sigma_{\text {change }}(\%)$} \\
\hline & SRES & SRES & SRES & SRES & SRES & SRES & SRES & SRES \\
\hline & A2 & B2 & A2 & B2 & A2 & B2 & A2 & B2 \\
\hline Region A & 4.95 & 4.17 & -12.8 & -16.5 & 6.81 & 4.67 & 13.6 & 16.7 \\
\hline Region B & 5.39 & 4.56 & -18.9 & -17.3 & 5.83 & 3.89 & 22.8 & 8.5 \\
\hline Region C & 3.83 & 3.33 & -4.5 & -14.6 & 6.56 & 4.88 & 12.0 & 7.3 \\
\hline Region D & 3.59 & 3.05 & -3.2 & -12.2 & 6.04 & 4.39 & 15.1 & 16.6 \\
\hline \multirow{4}{*}{$\begin{array}{l}\text { Total precipitation rate } \\
\text { (PRCP) }\end{array}$} & \multicolumn{4}{|c|}{ Winter season (DJF) } & \multicolumn{4}{|c|}{ Summer season (JJA) } \\
\hline & \multicolumn{2}{|c|}{$\mu_{\text {change }}(\%)$} & \multicolumn{2}{|c|}{$\sigma_{\text {change }}(\%)$} & \multicolumn{2}{|c|}{$\mu_{\text {change }}(\%)$} & \multicolumn{2}{|c|}{$\sigma_{\text {change }}(\%)$} \\
\hline & SRES & SRES & SRES & SRES & SRES & SRES & SRES & SRES \\
\hline & A2 & B2 & A2 & B2 & A2 & B2 & A2 & B2 \\
\hline Region A & 9.4 & 4.8 & 13.1 & 5.6 & -27.3 & -18.5 & -10.9 & -6.4 \\
\hline Region B & 8.7 & 9.7 & 4.6 & 10.6 & -2.7 & 8.4 & 17.1 & 16.1 \\
\hline Region C & 9.0 & 8.2 & 21.7 & 21.0 & -13.0 & -17.3 & -12.5 & -21.8 \\
\hline Region D & 8.5 & 6.2 & 20.5 & 18.6 & -5.7 & -2.7 & 4.7 & -5.4 \\
\hline
\end{tabular}

and Table S1 in the online supplement). However, the magnitude of summer warming in the higher emissions scenario is much larger than that in the lower scenario. The differences in the summer mean SAT between the two scenarios are an order of magnitude larger than those between different realizations from the future higher scenario ensemble. More intense warming is predicted in the northern regions (region $\mathrm{A}$ and $\mathrm{B}$ ) during the winter and in the western regions (regions A and C) during the summer, where the overestimates of the mean SAT relative to the CRU data also have larger magnitudes. The projected future changes in the mean SAT exceed the mean biases under either SRES A2 or SRES B2 scenario, though the magnitude of summer warming is only slightly larger than the overestimation over region $\mathrm{C}$ under the SRES B2 scenario. The width of the future SAT distributions will decrease in winter and increase in summer, indicating reduced and enhanced variability respectively.

\subsection{Precipitation response}

In contrast to the consistent increasing response of the SAT to greenhouse radiative forcing across the whole domain, the differences between the future and baseline PRCP climatology indicate both increasing and decreasing precipitation over different regions (Fig. 10). The future increases in the winter precipitation are statistically significant at the two-sided $\alpha=0.01$ level in the southern Canada and the east coast of the US. Winter precipitation is projected to decrease over the western part of the domain but the reduction is not significant. The changes in the summer precipitation climatology patterns depict a contrast between the northwestern and southeastern parts of the domain with significantly reduced precipitation over the northwestern inland regions and significantly enhanced precipitation over the ocean.

The PDFs of the future PRCP analyzed individually for the four regions are shown in Fig. 8 and the quantified changes are provided in Table 5. The four northeastern US regions are projected to experience a slight increase in winter precipitation under the future scenarios. For regions $\mathrm{A}, \mathrm{C}$ and $\mathrm{D}$, these projected changes (4.8-9.4\%) in winter precipitation are far less than the mean biases $(51.2-63.1 \%)$ relative to the CRU observed values. The projected winter precipitation changes for region B under the SRES A2 (8.7\%) and SRES B2 $(9.7 \%)$ scenarios have the same order of magnitude as the mean bias $(6.6 \%)$. These results are consistent with the findings by Rawlins et al. (2012), which indicate that all nine GCM-RCM pairs analyzed project wetter winter conditions across the nine northeast US states by midcentury, but the change in winter mean precipitation is less than the mean bias. With the exception of region $B$ under the SRES B2 scenario, summer precipitation is projected to decrease, with the relatively dry regions (regions $\mathrm{A}$ and $\mathrm{C}$ ) showing a greater decline. A winter precipitation increase of $8.7 \%$ and summer precipitation decrease of $-2.7 \%$ over the northeastern Region (B) projected by this PRECIS RCM under the SRES A2 scenario is in agreement with the ensemble-averaged precipitation changes from 9 AOGCM projections (Hayhoe et al. 2007). Rising summer temperature associated with decreasing summer rainfall may increase the frequency of short-term droughts, particularly under the 
Fig. 10 Projected future changes in the multiannual mean PRCP under the SRES A2 (a, e) and SRES B2 (b,

f) scenarios during winter (a,

b) and summer $(\mathbf{e}, \mathbf{f})$ seasons. c,

d, $\mathbf{g}, \mathbf{h}$ Regions where the change is significant at the twosided $\alpha=0.01$ level $(\alpha=0.1$ level) are shaded in red (cyan). The results presented for "RCM (HadAM3P) BL" and "RCM (HadAM3P) SRES A2" are based on one realization of the

3-member ensemble (a) RCM (HadAM3P) A2 - BL PRCP Change DJF

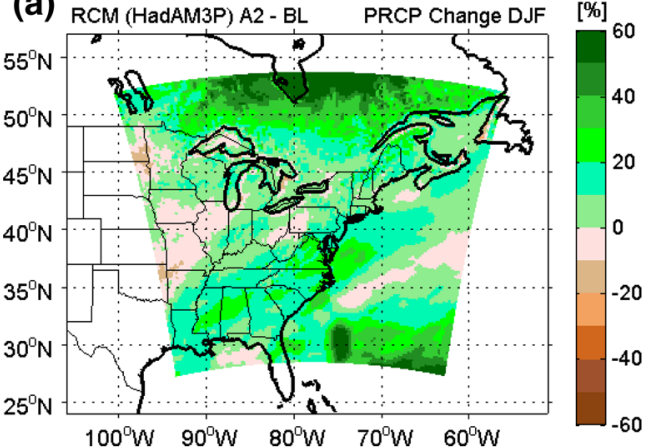

(b)

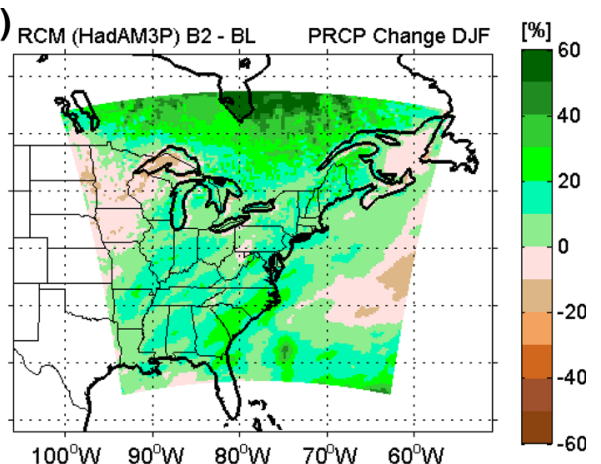

(c) RCM (HadAM3P) A2 - BL

PRCP Change DJF

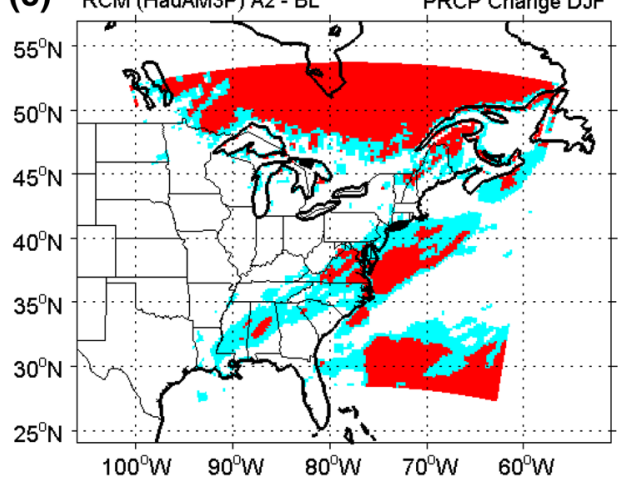

(d) RCM (HadAM3P) B2 - BL
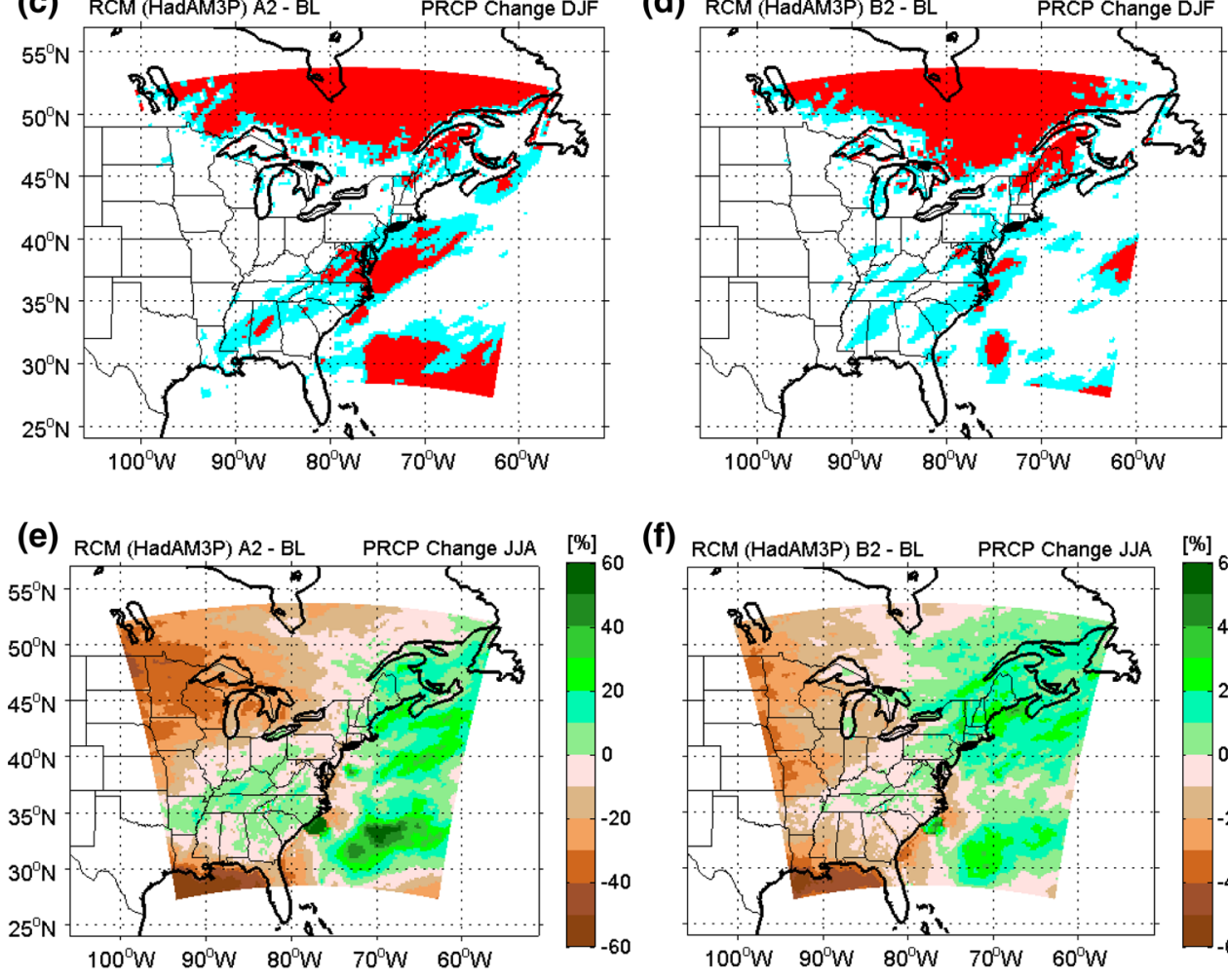

(g)

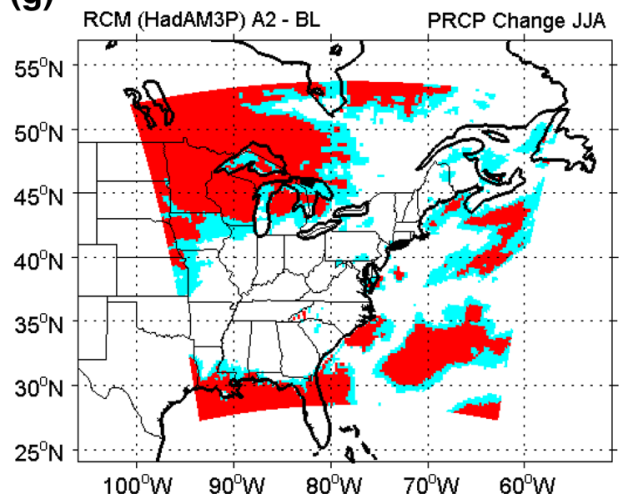

(f)

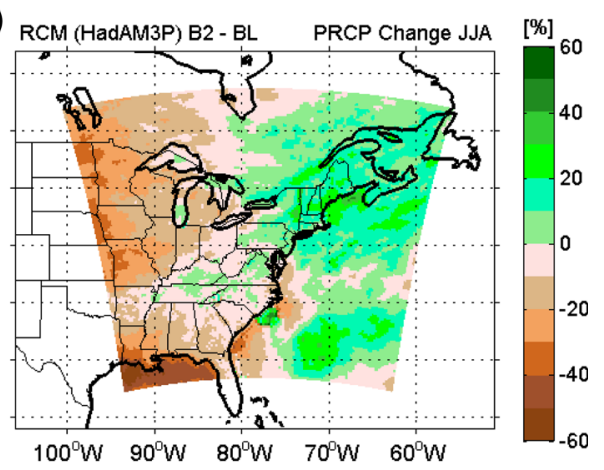

(h)

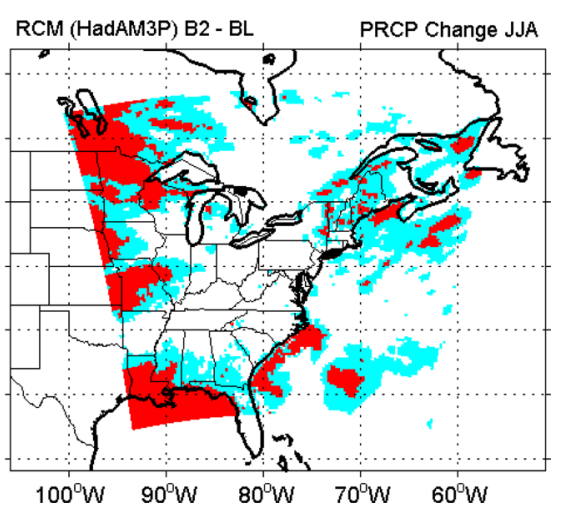

higher emissions scenario. Projected changes in the widths of the PDFs suggest an increase in the winter precipitation variability for all four regions. For the summer season, the relatively dry regions are not only projected to receive less precipitation, but also experience a decrease in the precipitation variability. 


\section{Conclusions}

Model validation for the thirty-year seasonal temperature and precipitation indicates that the RCM simulations generally capture the large-scale features, but their performance may vary seasonally and spatially across the domain. Relatively large warm biases are evident in the northern part of the domain during the winter and in the western part during the summer. The wet (dry) biases are particularly significant over the northwestern (western) regions during the winter (summer). Deficient precipitation simulated by the RCM simulations relative to the CRU data during the summer leads to the drying of the surface and higher sensible heat flux, and thus results in warm SAT biases. The RCM simulation forced by the quasi-observed boundary data (ERA40) shows better capabilities than those simulations forced by the GCM (HadAM3P) in reproducing observed temperature and precipitation with reduced warm biases and diminished wet (dry) biases during the winter (summer).

While the projected future increase in winter SAT is relatively insensitive to the emissions scenario uncertainty, the difference in the summer warming is more distinguishable between the higher and lower emissions scenarios. The projected summer temperature increase in this PRECIS RCM across the northeastern US region by the end of the twenty-first century $\left(5.83-6.81^{\circ} \mathrm{C}\right)$ is more than $3{ }^{\circ} \mathrm{C}$ greater than the summer warming projected by the ensemble mean of nine GCM-RCM pairs by the mid-century $\left(2.6^{\circ} \mathrm{C}\right.$ ) (Rawlins et al. 2012) under the SRES A2 scenario, suggesting a continuous temperature increase in response to greenhouse gas forcing. The projected future changes in precipitation indicate increasing winter precipitation and decreasing summer precipitation. However, less confidence is ascribed to the future precipitation changes over most parts of the northeastern US region due to the lack of statistical significance of the changes. The greater temperature increase under the higher emissions scenario than under the lower scenario indicates the importance of reducing emissions today to avoid dramatic climate changes and disastrous impacts over the course of the twentyfirst century.

Acknowledgments Funding for this research was provided by the Department of Interior's Northeast Climate Science Center, under USGS funding. We gratefully acknowledge the UK Hadley Centre scientists Simon Tucker, Chloe Morrell, David Hein, and Erasmo Buonomo for providing technical support. We also greatly appreciate Ambarish Karmalkar's constructive comments and suggestions on our manuscript.

Open Access This article is distributed under the terms of the Creative Commons Attribution License which permits any use, distribution, and reproduction in any medium, provided the original author(s) and the source are credited.

\section{References}

Bhaskaran B, Jones RG, Murphy JM, Noguer M (1996) Simulations of the Indian summer monsoon using a nested regional climate model: domain size experiments. Clim Dyn 12:573-587

Bukovsky MS, Karoly DJ (2007) A brief evaluation of precipitation from the North American Regional Reanalysis. Clim Dyn 8:837-846

Cox PM, Betts RA, Bunton CB, Essery RLH, Rowntree PR, Smith J (1999) The impact of new land surface physics on the GCM simulation of climate and climate sensitivity. Clim Dyn 15(3):183-203

Fogarty M, Incze L, Hayhoe K, Mountain D, Manning J (2008) Potential climate change impacts on Atlantic cod (Gadus morhua) off the northeastern USA. Mitig Adapt Strat Glob Change 13:453-466

Frumhoff PC, McCarthy JJ, Melillo JM, Moser SC, Wuebbles DJ, Wake C, Spanger-Siegfried E (2008) An integrated climate change assessment for the Northeast United States. Mitig Adapt Strat Glob Change 13:419-423

Gordon C, Cooper C, Senior CA, Banks H, Gregory JM, Johns TC, Mitchell JFB, Wood RA (2000) The simulation of SST, sea ice extents and ocean heat transports in a version of the Hadley Centre coupled model without flux adjustment. Clim Dyn 16:147-168

Hayhoe K, Wake CP, Huntington TG, Luo L, Schwartz MD, Sheffield J, Wood E, Anderson B, Bradbury J, DeGaetano A et al (2007) Past and future changes in climate and hydrological indicators in the US Northeast. Clim Dyn 28:381-407

Hewitson BC, Crane RG (2006) Consensus between GCM climate change projections with empirical downscaling: precipitation downscaling over South Africa. Int J Climatol 26:1315-1337

Iverson L, Prasad A, Matthews S (2008) Modeling potential climate change impacts on the trees of the northeastern United States. Mitig Adapt Strat Glob Change 13:487-516

Jones RG, Murphy JM, Noguer M (1995) Simulation of climate change over Europe using a nested regional-climate model. I: assessment of control climate, including sensitivity to location of lateral boundaries. Q J R Meteor Soc 121:1413-1449

Jones RG, Noguer M, Hassell DC, Hudson D, Wilson SS, Jenkins GJ, Mitchell JFB (2004) Generating high resolution climate change scenarios using PRECIS. Met Office Hadley Centre, Exeter

Karmalkar AV, Bradley RS, Diaz HF (2011) Climate change in Central America and Mexico: regional climate model validation and climate change projections. Clim Dyn 37:605-629. doi:10. 1007/s00382-011-1099-9

Kirshen P, Watson C, Douglas E, Gontz A, Lee J, Tian Y (2008) Coastal flooding in the Northeastern United States due to climate change. Mitig Adapt Strat Glob Change 13:437-451

McCarthy MP, Harpham C, Goodess CM, Jones PD (2011) Simulating climate change in UK cities using a regional climate model, HadRM3. Int J Climatol 32:1875-1888

Mearns LO, Gutowski WJ, Jones R, Leung LR, McGinnis S, Nunes A, Qian Y (2009) A regional climate change assessment program for North America. EOS Trans AGU 90(36):311-312

Mearns LO, Arritt R, Biner S, Bukovsky MS, McGinnis S, Sain S, Caya D, Correia J Jr, Flory D, Gutowski W et al (2012) The North American regional climate change assessment program: overview of phase I results. Bull Am Meteor Soc 93:1337-1362. doi:10.1175/BAMS-D-11-00223.1

Mesinger F et al (2006) North American regional reanalysis. Bull Am Meteor Soc 87:343-360

Nakićenović N, Alcamo J, Davis G, de Vries B, Fenhann J, Gaffin S, Gregory K, Grübler A, Jung TY, Kram T et al (2000) Special report on emissions scenarios: a special report of Working Group 
III of the Intergovernmental Panel on Climate Change. Cambridge University Press, Cambridge

Ning L, Mann ME, Crane R, Wagener T, Najjar RG Jr, Singh R (2012) Probabilistic projections of anthropogenic climate change impacts on precipitation for the mid-Atlantic region of the United States. J Clim 25:5273-5291

Rawlins MA, Bradley RS, Diaz HF (2012) Assessment of regional climate model simulation estimates over the northeast United States. J Geophys Res 117:D23112. doi:10.1029/2012JD018137

Rayner NA, Parker DE, Horton EB, Folland CK, Alexander LV, Rowell DP, Kent EC, Kaplan A (2003) Global analyses of sea surface temperature, sea ice, and night marine air temperature since the late nineteenth century. J Geophys Res 108(D14):4407. doi: $10.1029 / 2002 J D 002670$

Rowell DP (2005) A scenario of European climate change for the late twenty-first century: seasonal means and interannual variability. Clim Dyn 25:837-849. doi:10.1007/s00382-005-0068-6

Schwartz MD, Ahas R, Aasa A (2006) Onset of spring starting earlier across the Northern Hemisphere. Glob Change Biol 12:343-351
Simmons AJ, Burridge DM (1981) An energy and angular-momentum conserving vertical finite difference scheme and hybrid vertical coordinates. Mon Weather Rev 109:758-766

Urrutia R, Vuille M (2009) Climate change projections for the tropical Andes using a regional climate model: temperature and precipitation simulations for the end of the 21 st century. J Geophys Res 114:D02108. doi:10.1029/2008JD011021

Wilson MF, Henderson-Sellers A (1985) A global archive of land cover and soils data for use in general circulation models. J Climatol 5:119-143

Wilson SS, Hassell DC, Hein D, Morrell C, Tucker S, Jones RG, Taylor RBE (2011) Installing and using the Hadley Centre regional climate modeling system, PRECIS (version 1.9.3), Met Office Hadley Centre, Exeter

Xie P, Arkin PA (1997) Global precipitation: a 17-year monthly analysis based on gauge observations, satellite estimates and numerical model outputs. Bull Am Meteor Soc 78:2539-2558 